\title{
Innovative Instrumentation and Analysis of the Temperature Measurement for High Temperature Gasification
}

\section{Type of Report: Semi-Annual Technical Report}

Reporting Period Starting Date: 4/1/2005

Reporting Period End Date: 9/30/2005

Principal Author(s): $\quad$ Dr. Seong W. Lee

Date Report was issued: October 2005

DOE Award Number: DE-PS26-02NT41681

Name and Address of Submitting Organization:

Morgan State University

School of Engineering

5200 Perring Parkway

Baltimore, MD 21239 


\section{DISCLAIMER}

This report was prepared as an account of work sponsored by an agency of the United States Government. Neither the United States Government nor any agency thereof, nor any of their employees, makes any warranty, express or implies, or assumes any legal liability or responsibility for the accuracy, completeness, or usefulness of any information, apparatus, product, or process disclosed, or represents that its use would not infringe privately owned rights. Reference herein to any specific commercial product, process, or service by trade name, trademark, manufacturer, or otherwise does not necessarily constitute or imply its endorsement, recommendation, or favoring by the United States Government or any agency thereof. The views and opinions of authors expressed herein do not necessarily state or reflect those of the United States Government or any agency thereof. 


\begin{abstract}
The objectives of this project during this semi-annual reporting period are to test the effects of coating layer of the thermal couple on the temperature measurement and to screen out the significant factors affecting the temperature reading under different operational conditions. The systematic tests of the gasifier simulator on the high velocity oxygen fuel (HVOF) spray coated thermal couples were completed in this reporting period. The comparison tests of coated and uncoated thermal couples were conducted under various operational conditions. The temperature changes were recorded and the temperature differences were calculated to describe the thermal spray coating effect on the thermal couples. To record the temperature data accurately, the computerized data acquisition system (DAS) was adopted to the temperature reading. The DAS could record the data with the accuracy of $0.1{ }^{\circ} \mathrm{C}$ and the recording parameters are configurable. In these experiments, DAS was set as reading one data for every one (1) minute.
\end{abstract}

The operational conditions are the combination of three parameters: air flow rate, water/ammonia flow rate and the amount of fine dust particles. The results from the temperature readings show the temperature of uncoated thermal couple is uniformly higher than that of coated thermal couple for each operational condition.

Analysis of Variances (ANOVA) was computed based on the results from systematic tests to screen out the significant factors and/or interactions. The temperature difference was used as dependent variable and three operational parameters (i.e. air flow rate, water/ammonia flow rate and amount of fine dust particle) were used as independent factors. The ANOVA results show that the operational parameters are not the statistically significant factors affecting the temperature readings which indicate that the coated thermal couple could be applied to temperature measurement in gasifier. The actual temperature reading with the coated thermal couple in the gasification could be calibrated by a constant of temperature difference. 


\section{TABLE OF CONTENTS}

\section{$\underline{\text { Page }}$}

TITLE PAGE i

DISCLAIMER ii

ABSTRACT iii

TABLE OF CONTENTS iv

1. INTRODUCTION 1

2. EXECUTIVE SUMMARY 5

3. EXPERIMENTAL 7

3.1. Gasifier Simulator Systematic Experiment 7

$\begin{array}{ll}\text { 3.1.1. System Setup } & 7\end{array}$

3.2. Data Acquisition System (DAS) 7

$\begin{array}{ll}\text { 3.2.1. Design of DAS } & 7\end{array}$

3.3. Temperature Measurements with the Coated Thermal Couple 11

3.3.1. Experimental Design 11

3.3.2. Test Results 11

4. RESULTS AND DISCUSSION 12

$\begin{array}{ll}\text { 4.1. Test Results } & 12\end{array}$

4.2. Effect of the Coated Thermal Couple on the Temperature Measurements

4.3. Analysis of Variance (ANOVA) 18

5. CONCLUSIONS

REFERENCES 22

$\begin{array}{ll}\text { Appendix I } & 23\end{array}$

$\begin{array}{lr}\text { Appendix II } & 24\end{array}$ 


\section{INTRODUCTION}

The establishment of the coating on the surface will greatly improve the character of abrasion resistance, erosion resistance, heat resistance, chemical resistance regarding the part and the product. It can also give the character of the electric conductivity, insulation, and thermal conduction control.

The thermal spray coating process takes the energy from the inflammable gas, ionized gas, explosive gas, or electric energy, and heats the spray powder to a sufficient point (not necessarily to melting) whereby the feed stock will deform on impact [1]. It is propelled by the energy source gas stream at a target that the feed stock literally explodes onto the target, cools and forms a mechanical bond on the surface. Different heat sources determine the different spray processes [2]. Figure 1 illustrates the breakdown of different thermal spray processes. Basically, the thermal spray process includes the electric heat source and chemical (combustion) source due to the heat generation sources. The electric heat source includes plasma spray and wire arc spray. The plasma spray process is basically the spraying of molten or heat softened material onto a surface to provide a coating [3]. The wire Arc spray process uses the electric arc to melt a pair of electrically conductive wires. The molten material is atomized by compressed air and propelled towards the substrate surface. The chemical (combustion) heat source includes flame spray, high velocity oxygen fuel (HVOF) spray and detonation gun spray [4]. The flame spray and detonation gun basically consist of a long water cooled barrel with inlet valves for gases and powder. Oxygen and fuel (acetylene most common) is fed into the barrel along with a charge of powder [2,3]. 


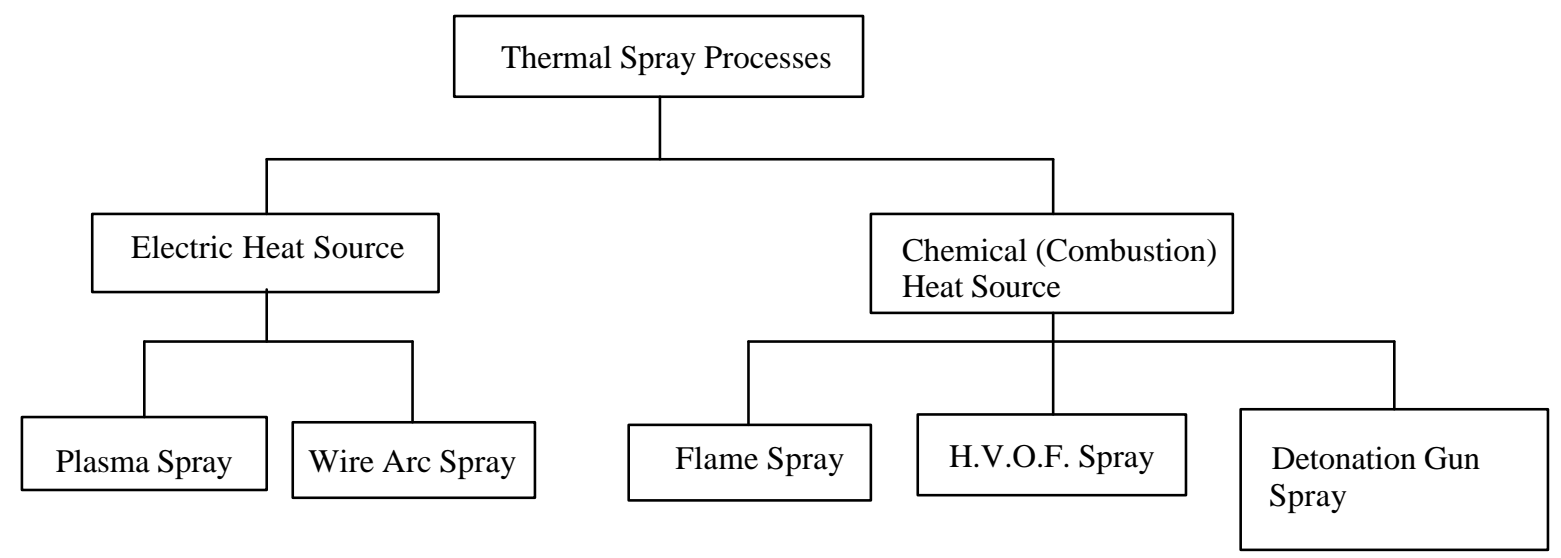

Figure 1. Schematic Flow Chart of the Different Thermal Spray Processes

The HVOF (high velocity oxygen fuel) thermal spray process is the same as the combustion powder spray process except that this process has been developed to produce an extremely high spray velocity. There are a number of HVOF guns which use different methods to achieve high velocity spraying [4]. One method is basically a high pressure water cooled combustion chamber and long nozzle. Fuels (kerosene, acetylene, propylene and hydrogen) and oxygen are fed into the chamber, and combustion process produces a hot high pressure flame which is forced down a nozzle increasing its velocity. Powder may be fed axially into the combustion chamber under high pressure or fed through the side of laval type nozzle where the pressure is lower. Another method uses a simpler system of a high pressure combustion nozzle and air cap. Fuel gas (e.g. propane, propylene or hydrogen) and oxygen are supplied at high pressure. Combustion occurs outside the nozzle but within an air cap supplied with compressed air. The compressed air pinches and accelerates the flame and acts as a coolant for the gun. Powder is fed at high pressure axially from the center of the nozzle. Figure 2 shows the HVOC process. 


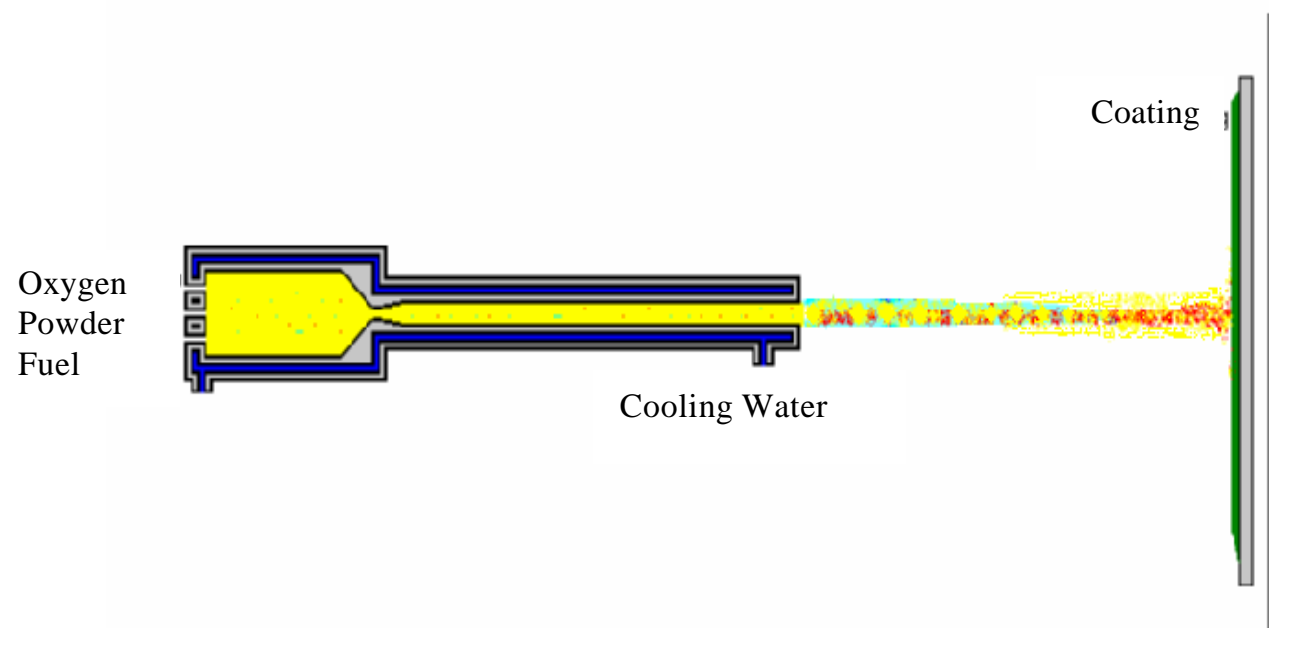

Figure 2 Schematic Diagram of the HVOF Process

The major advantage of HVOC process is that the coatings are very dense, strong and low residual tensile stress, which enables thicker coatings to be applied than the other processes.

The very high kinetic energy of particles striking the substrate surface do not require the particles to be fully molten to form high quality coatings. This is certainly an advantage for the carbide cermets type coatings and is where this process really excels[5]. HVOF coatings are used in applications requiring the highest density and strength not found in most other thermal spray processes. New applications, previously not suitable for thermal spray coatings are becoming viable.

HVOF spray technologies for application of tungsten carbide and chrome carbide based coatings have proved to be cleaner and more effective than chrome plating. Their superior performance is predicted to lead to significant reductions in life-cycle cost of ownership in industry. Development of Activated Combustion HVOF technology is expected to become a "break-through" in thermal spray applications for hard chrome replacement since this novel technology overcomes above-mentioned problems [6,7]. 
The anti-erosion/corrosion coating sprayed on the thermocouple could make the thermocouple specialized and unique. The High Velocity Oxygen Flame (HVOF) coatings are used in applications requiring the highest density and strength not found in most other thermal spray processes [8]. HVOF Spraying is essentially a variation of powder flame spraying in which a modified torch is used to constrict the gas flow. HVOF coatings are usually denser and have higher bond strengths than coatings produced by other processes. This is particularly useful when tough, wear resistant coatings, such as tungsten carbide, are required. HVOF spray process ensures that the coating layer on the thermal couple tips are low-cost and reliable. Figure 3 shows the coated thermal couple via HVOF thermal spraying process, which is used for the experiment tests.

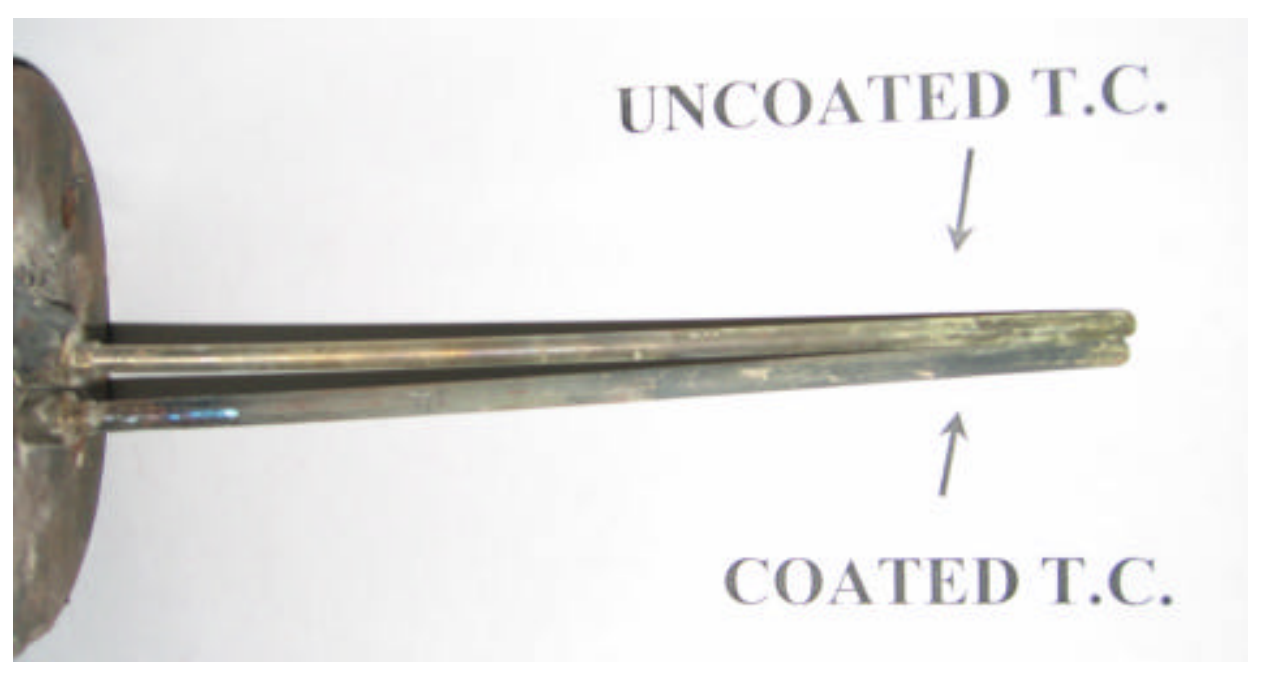

Figure 3. Pictorial view of Coated and Uncoated Thermal Couples 


\section{EXECUTIVE SUMMARY}

The systematic tests of the gasifier simulator on the high velocity oxygen fuel (HVOF) spray coated thermal couples were completed in this reporting period. The coated thermal couple and uncoated thermal couple were amounted together to measure the temperature at the same location. The temperature changes along with the experimental time were recorded. The computerized data acquisition system (DAS) was adopted to record the temperature data accurately. The DAS could record the data with the accuracy of $0.1{ }^{\circ} \mathrm{C}$ and the recording time was set as reading one data for every one (1) minute.

The operational conditions are the combination of three parameters: (1) air flow rate, (2) water/ammonia flow rate and (3) the amount of fine dust particles. Each parameter has two (2) levels. A total of eight experiments were scheduled according to the full factorial design theorem. The results from the temperature readings show the temperature of uncoated thermal couple is uniformly higher than that of coated thermal couple for each operational condition. It is believed that the coating layer will increase the heat resistance between the thermal couple tip and the object. The increased heat resistance affects the temperature difference.

Analysis of variance (ANOVA) is used to identify the significant factors and interactions affecting on the dependent variable (i.e. temperature difference). Analysis of Variance (ANOVA) was computed based on the results from systematic tests. The temperature difference was used as dependent variable and three operational parameters (i.e. air flow rate, water/ammonia flow rate and amount of fine dust particle) were used as independent factors. The ANOVA results show that there are no significant factors or 
interactions affecting the temperature readings at the type I error of $\alpha=0.05$, indicating that the coated thermal couple could be applied to the temperature measurements in the gasifier. Therefore, it is concluded that the coated thermal couple could be used to measure the temperature in the reducing and harsh environment. 


\section{EXPERIMENTAL}

\subsection{Gasification Simulator Systematic Experiment}

\subsubsection{System Setup}

The experimental facilities used in this period were discussed in previous reports

and research papers [8-9]. The systematic experiments regarding water injection flow rate and air injection rate were discussed in the previous report III [9]. From the previous results, the air injection rate was a significant factor affecting the temperature reading in the gasifier simulator; the water injection flow rate was not a significant factor affecting the temperature reading. The interaction between water injection rate and air injection rate did not affect the temperature readings in the gasifier simulator [10].

In this progress report, the coated thermal couple was used to test the coating effects on the temperature measurement. The comparison tests were conducted in order to analyze the difference in the temperature readings. The computerized data acquisition system was designed and applied to the gasification simulator system. In order to test how the coating affects the temperature reading, the experiments was designed and conducted in this period.

\subsection{Data Acquisition System (DAS)}

\subsubsection{Design of DAS}

The OMB-DAQ-54 Data Acquisition System (DAS) is used to record the temperature measurement accurately and automatically. The OMB-DAQ-54 Data Acquisition System (DAS) is attached to the whole gasification simulator. The OMBDAQ-54 Data Acquisition System (DAS) is a fultfeatured data acquisition product that utilizes the Universal Serial Bus (USB), which is built into almost every new personal 
computer. Designed for high accuracy and resolution, the 22-bit OMB-DAQ-54 data acquisition systems directly measure multiple channels of thermocouple, voltage, pulse, frequency. A single cable to the PC provides high-speed communication and power to the OMB-DAQ-54. The OMB-DAQ-54 avoids many of the limitations of PC-Card (PCMCIA) data acquisition devices and offer advantages over many PC plug-in data acquisition boards as well [11].

The OMB-DAQ-54 data acquisition system offers ten single-ended or five (5) differential analog (up to $\pm 20 \mathrm{~V}$ full scale) or thermocouple input channels with 16 programmable ranges and $500 \mathrm{~V}$ optical isolation as shown in Figure 4. To simplify attachment of signals and transducers, the OMB-DAQ-54 modules feature convenient, removable screw-terminal input connections.

Personal DaqView allows the creation of real-time displays using built-in display options, including digital, dial meter, bar graph, and strip chart displays. Thermocouple type and temperature ranges: $\mathrm{K}\left(-200\right.$ to $\left.1200^{\circ} \mathrm{C}\right)$, and thermocouple accuracy: $\mathrm{K}$ $\left( \pm 1.2^{\circ} \mathrm{C}\right)$. Figure 4 shows the pictorial view of the OMB-DAQ-54 module.

The schematic diagram of the whole gasification simulator system with the temperature data acquisition subsystem is shown in Figure 5. The coated and uncoated thermal couples are connected directly to the OMB-DAQ-54 module. Two out of five provided channels are used for the temperature measurement. The module is connected to a personal computer through a universal series bus (USB). The pictorial view of the whole system is illustrated in Figure 6. 


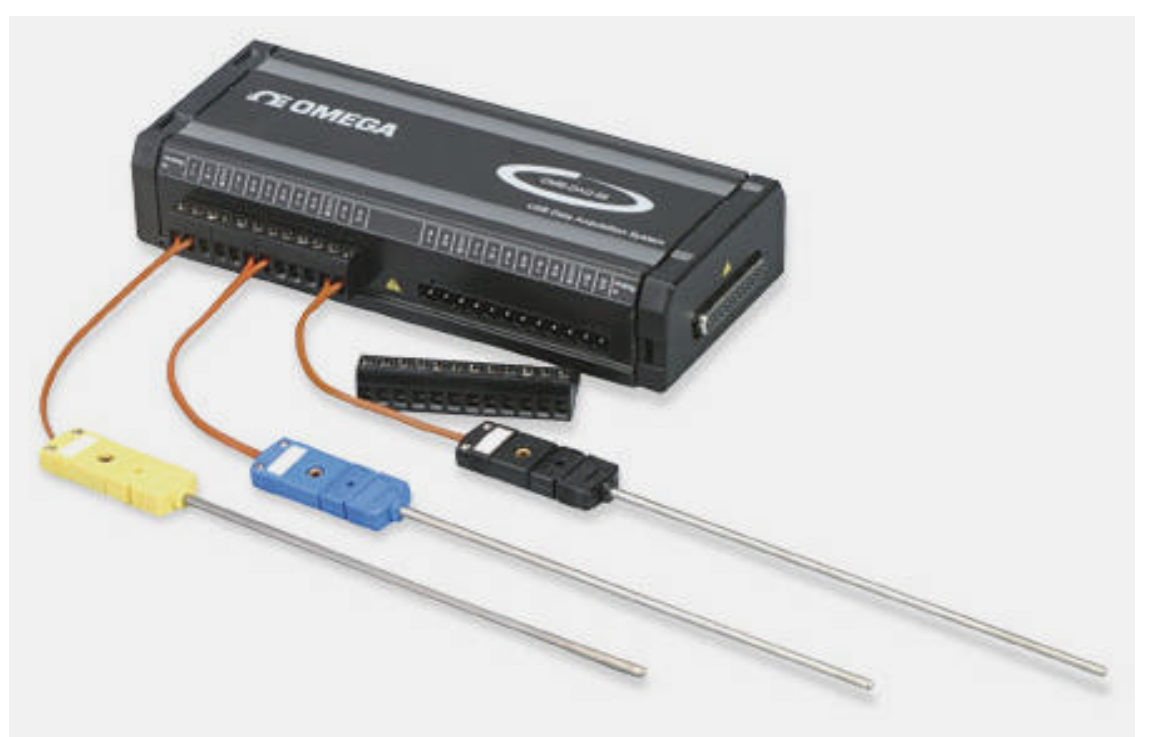

Figure 4. Pictorial View of OMB-DAQ-54 Data Acquisition Module

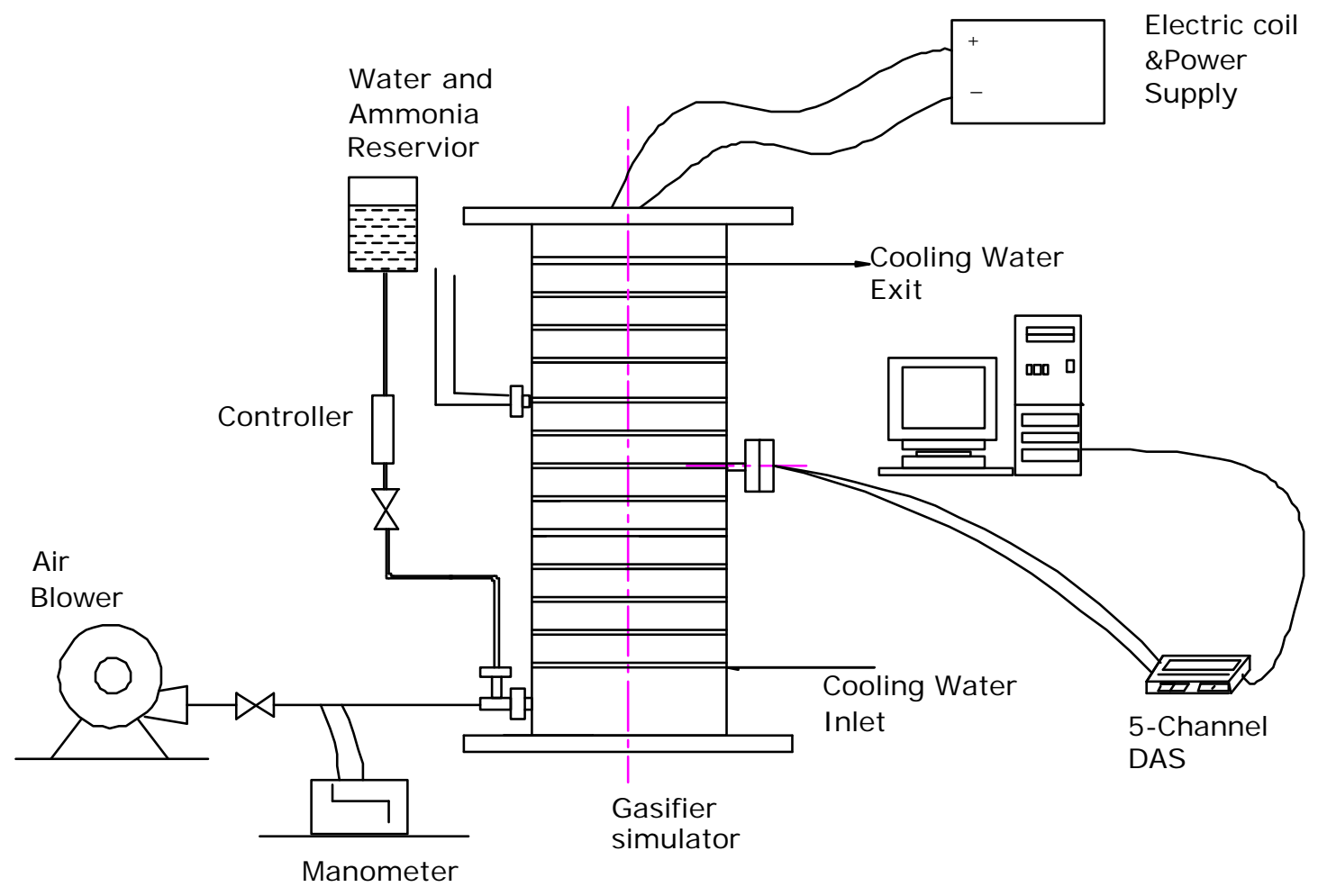

Figure 5 Schematic Diagram of Gasification System with 5-channel DAS 


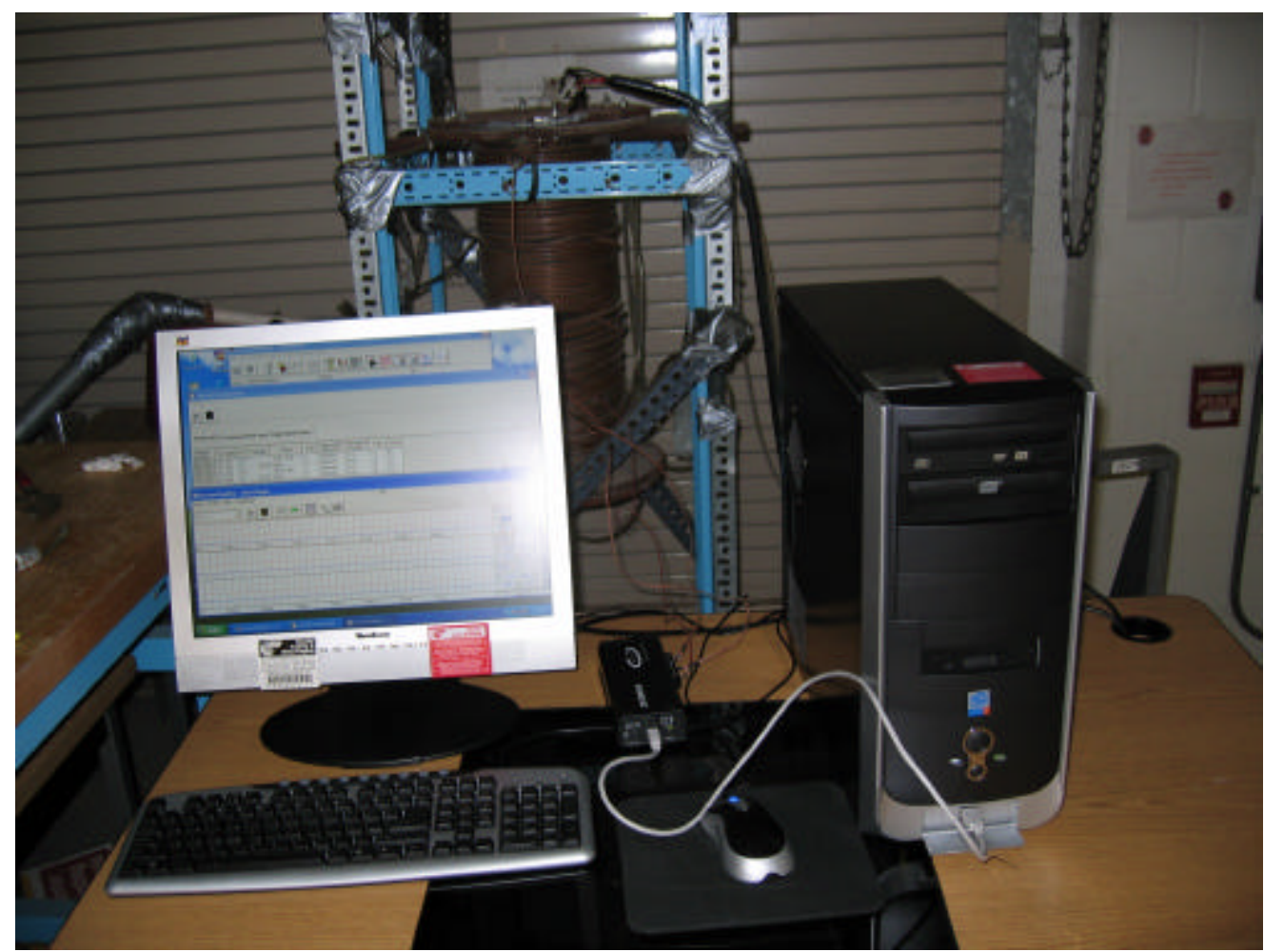

Figure 6 Pictorial View of the Gasifier Simulation System with 5-channel DAS

The Personal DaqView with the associated authorization code is the attached software for the OMB-DAQ-54 module. The Personal DaqView is window-based software which can be installed in Microsoft Windows 98SE/WindowsME/2000 or XP. Figure 7 is an illustration of 5-channel DAS and DaqView interfaces.
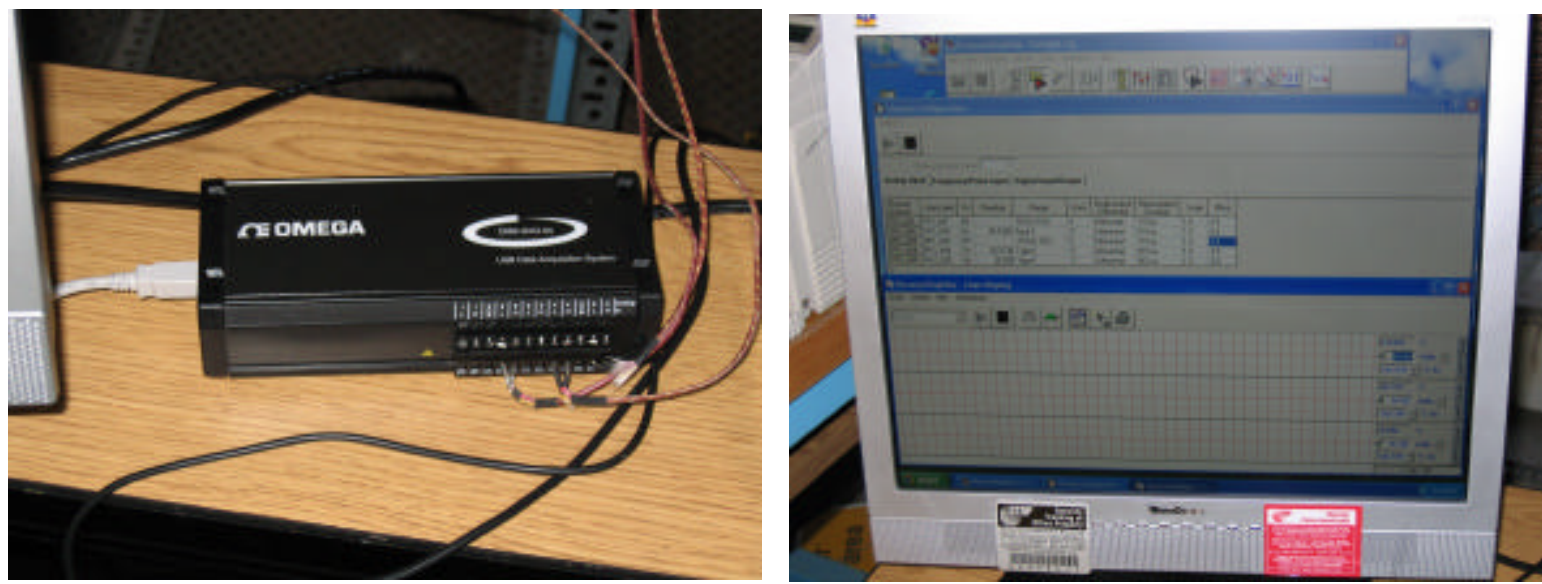

Figure 7. Pictorial View of 5-channel DAS and Personal DaqView 


\subsection{Temperature Measurements with the Coated Thermal Couple}

\subsubsection{Experimental Design}

The reliable and cost effective high velocity oxygen fuel (HVOF) spraying coated thermal couple is applied to this gasification temperature measurement to test its characteristics. The experiments are designed with reference to different operation conditions. The operational conditions refering to the effecting factors include water/ammonia flow rate, air flow rate and the amount of dust particles. Two thermal couples are mounted together at the same location in order to be able to compare the temperature measurements with each other. The temperature changes are recorded for every five minutes from the start time to end time under each operation condition. The end time is identified as the condition under which the temperature change falls within \pm 5 ${ }^{o} \mathrm{~F}$ per five minutes. This criterion is derived from the previous experiments. The test matrix is shown in Table 1.

Table 1. Test Matrix of the Experimental Conditions

\begin{tabular}{|c|c|c|c|}
\hline \multirow{2}{*}{$\begin{array}{c}\text { No. of } \\
\text { experiments }\end{array}$} & Air flow & $\begin{array}{c}\text { Ammonia/water } \\
\text { flow }\end{array}$ & $\begin{array}{c}\text { Fine dust particles } \\
\text { amount }\end{array}$ \\
\cline { 2 - 4 } & Voltage & Ml/minute & gram \\
\hline 1 & 15 & 2 & 75 \\
\hline 2 & 10 & 2 & 75 \\
\hline 3 & 15 & 3 & 75 \\
\hline 4 & 10 & 3 & 75 \\
\hline 5 & 15 & 2 & 150 \\
\hline 6 & 10 & 2 & 150 \\
\hline 7 & 15 & 3 & 150 \\
\hline 8 & 10 & 3 & 150 \\
\hline
\end{tabular}




\section{RESULTS AND DISCUSSION}

\subsection{Tests Results}

Appendix 1 shows temperature measurements data under three conditions. The experimental conditions are identified by various factors including air flow, water/ammonia flow and fine dust particles. Each factor has two levels. The air flow is categorized into two levels with 15 voltages and 10 voltages. Water/ammonia flow rate is $2 \mathrm{ml} /$ minute and $3 \mathrm{ml} /$ minute. The fine dust particles are 75 grams and 150 grams, respectively. Figure 8 shows the comparison test of coated and uncoated thermal couples under the condition: 15 voltages for air flow, $2 \mathrm{ml} / \mathrm{min}$ for ammonia \& water, and 75 grams for fine dust particles.

\subsection{Effects of the Coated Thermal Couple on the Temperature Measurements}

The temperature readings of coated and uncoated thermal couples are identical throughout the test time as shown in Figure 8. The temperature for uncoated thermal couple is uniformly higher than that of the coated thermal couple. The average temperature difference is $8.7^{\circ} \mathrm{C}$ for this condition.

Figure 9 shows the comparison test of coated and uncoated thermal couples under the condition: 10 voltages for air flow, $2 \mathrm{ml} / \mathrm{min}$ for ammonia \& water, and 75 gram for fine dust particles. The temperature changes indicate identical temperature readings for coated and uncoated thermal couples throughout the testing. The temperature for uncoated thermal couple is uniformly higher than that of the coated thermal couple. The average temperature difference is $15.4{ }^{\circ} \mathrm{C}$ for this condition. It is believed that the coating layer will increase the heat resistance between the thermal couple tip and the object. The increased heat resistance affects the temperature difference. 


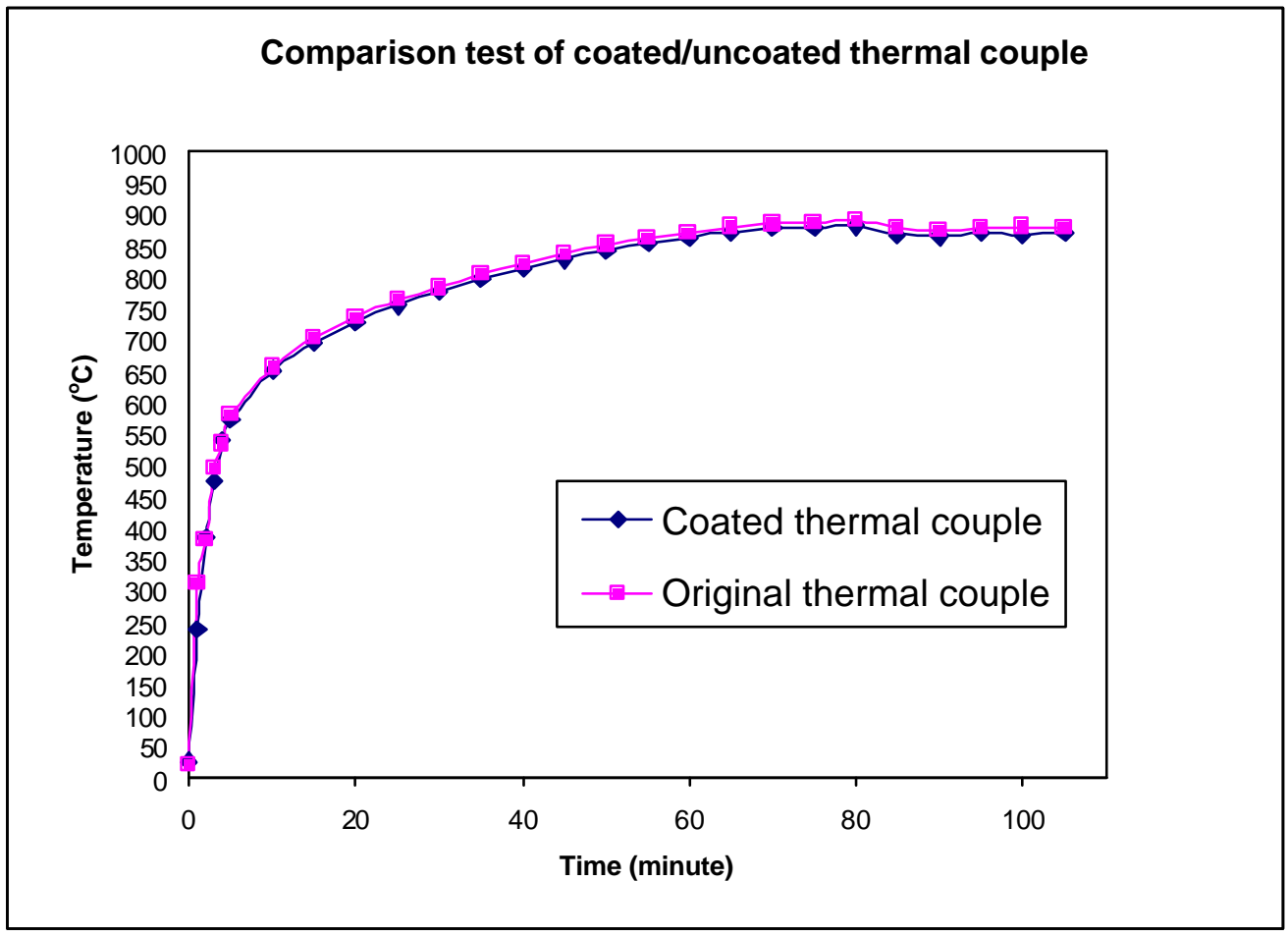

Figure 8 Comparison Tests on Temperature Measurement for Coated/Uncoated Thermocouples

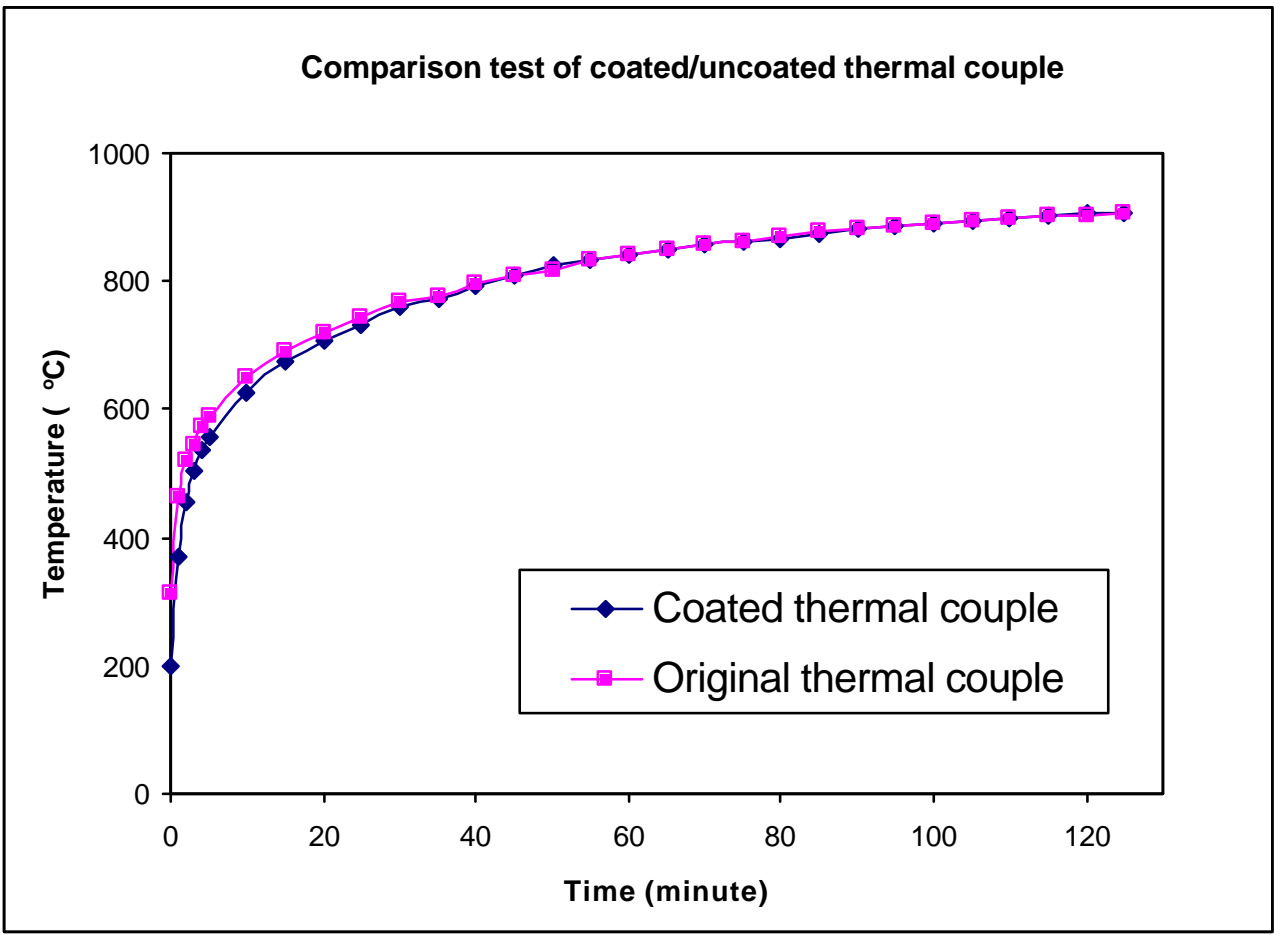

Figure 9 Comparison Tests on Temperature Measurement for Coated/Uncoated Thermocouples 
Figure 10 shows the comparison test of coated and uncoated thermal couples under the condition: 15 voltages for air flow, $3 \mathrm{ml} / \mathrm{min}$ for ammonia \& water, and 75 gram for fine dust particles. The temperature plots also show the identical distribution of the temperature readings for coated and uncoated thermal couples throughout the testing. The temperature for uncoated thermal couple is uniformly higher than the temperature for coated thermal couple. The average temperature difference is $9.4{ }^{\circ} \mathrm{C}$ for this condition.

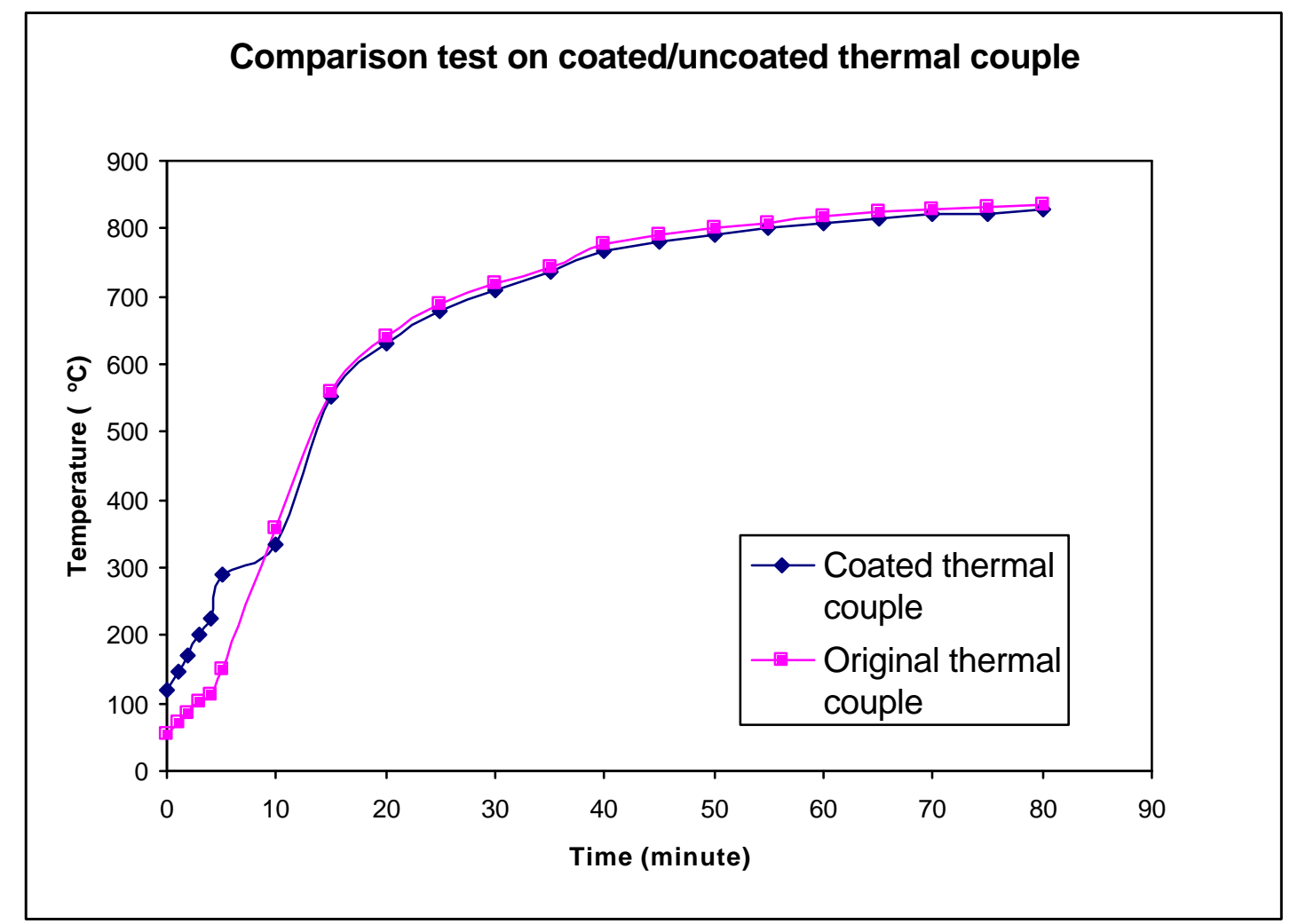

Figure 10 Comparison Tests on Temperature Measurement for Coated/Uncoated Thermocouples

After the installation of data acquisition system (DAS), additional experiments are continued as shown in Table 1. The details of the temperature changes are attached in Appendix 2. 
Figure 11 shows the comparison test of coated and uncoated thermal couples under the condition: 10 voltages for air flow, $3 \mathrm{ml} / \mathrm{min}$ for ammonia \& water, and 75 gram for fine dust particles. The temperature plots also show the identical of the temperature readings for coated and uncoated thermal couples throughout the testing time interval. The temperature changes for uncoated thermal couple are uniformly higher than that o the coated thermal couple. The average temperature difference is $23.2 \mathrm{C}$ for this condition.

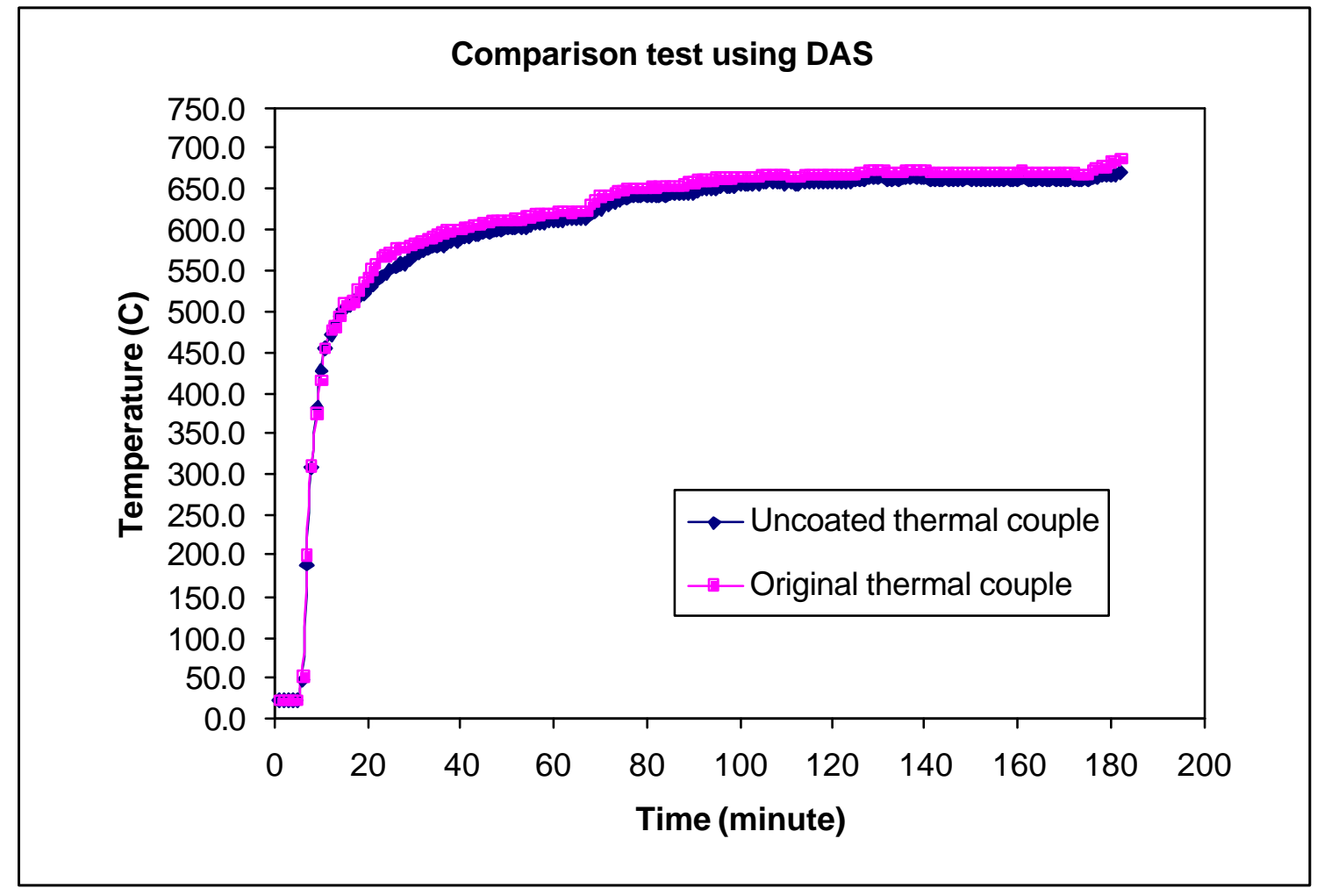

Figure 11 Comparison Tests of Coated/Uncoated Thermal Couple with DAS

Figures 12-15 show the comparison tests of coated and uncoated thermal couples under the conditions of 150 grams for fine dust particles and four full combinations of different levels of the air flow and ammonia/water. The experiment conditions are shown in Table 1 for the experimental observations of number 5 to 8 . The temperature plots also 
show the identical of the temperature readings for coated and uncoated thermal couples throughout the tests. The temperature for uncoated thermal couple is uniformly higher than that of the coated thermal couple. The average temperature differences for these conditions are shown in Table 2.

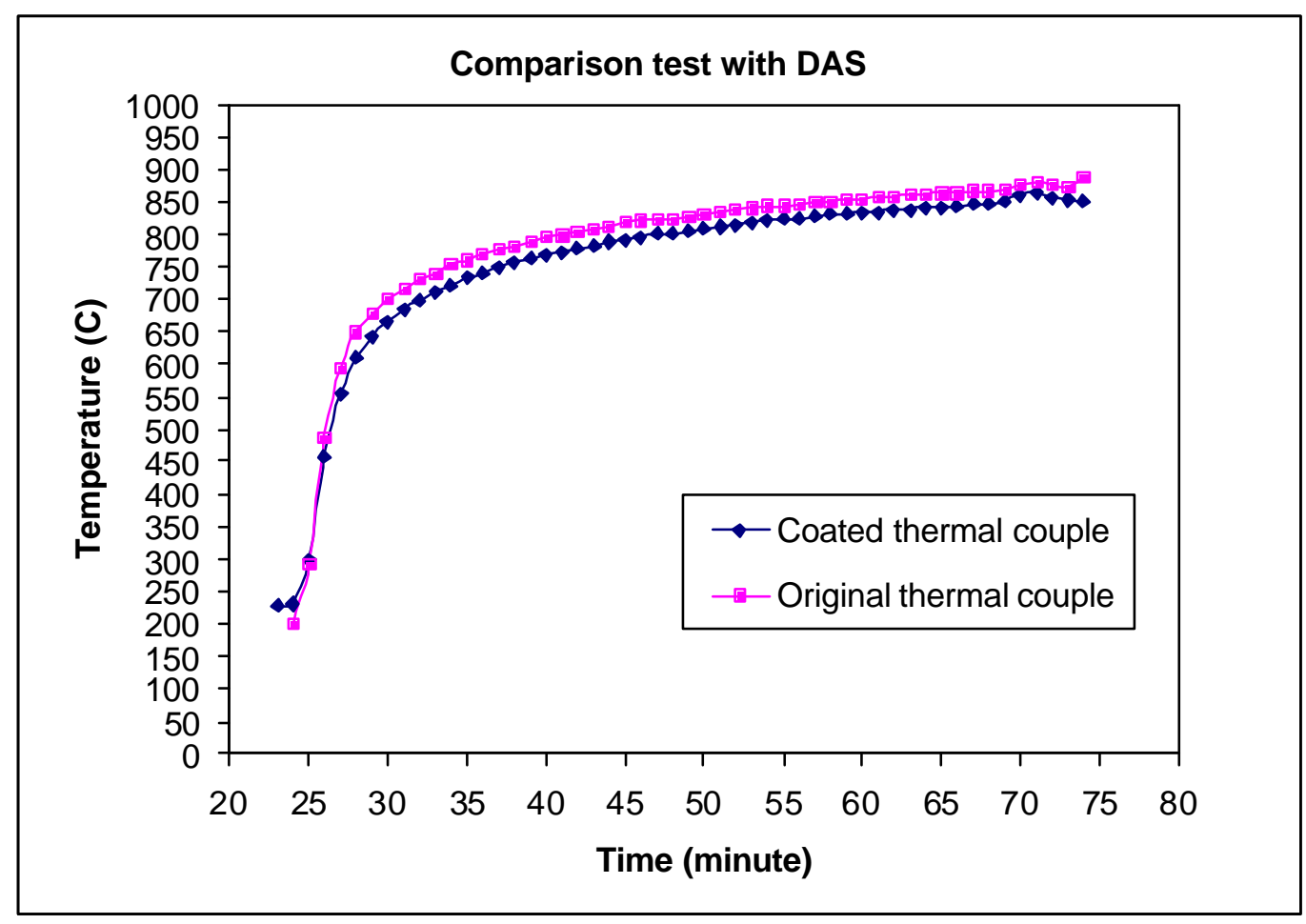

Figure 12 Comparison Tests of Coated/Uncoated Thermal Couple with DAS 


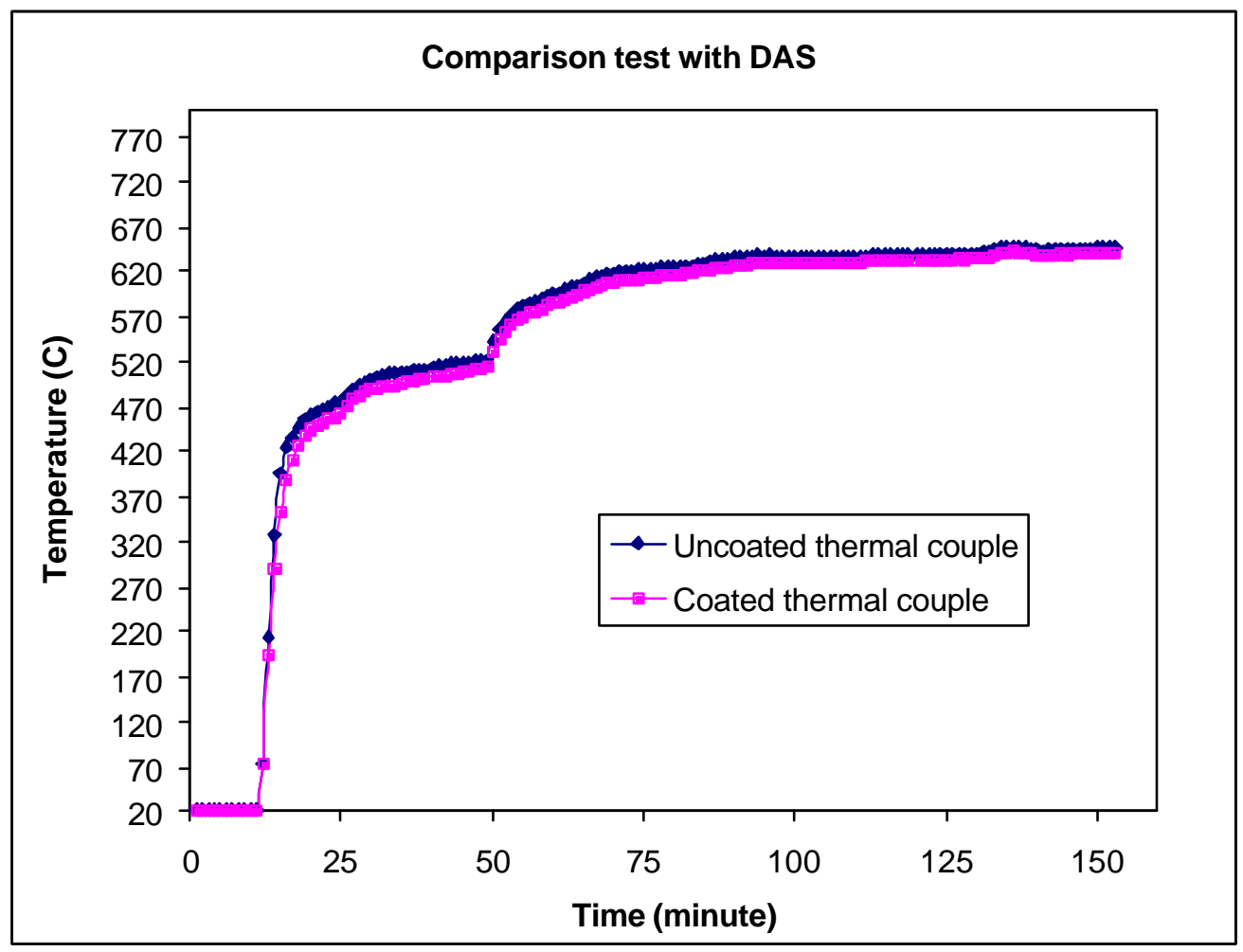

Figure 13 Comparison Tests of Coated/Uncoated Thermal Couple with DAS

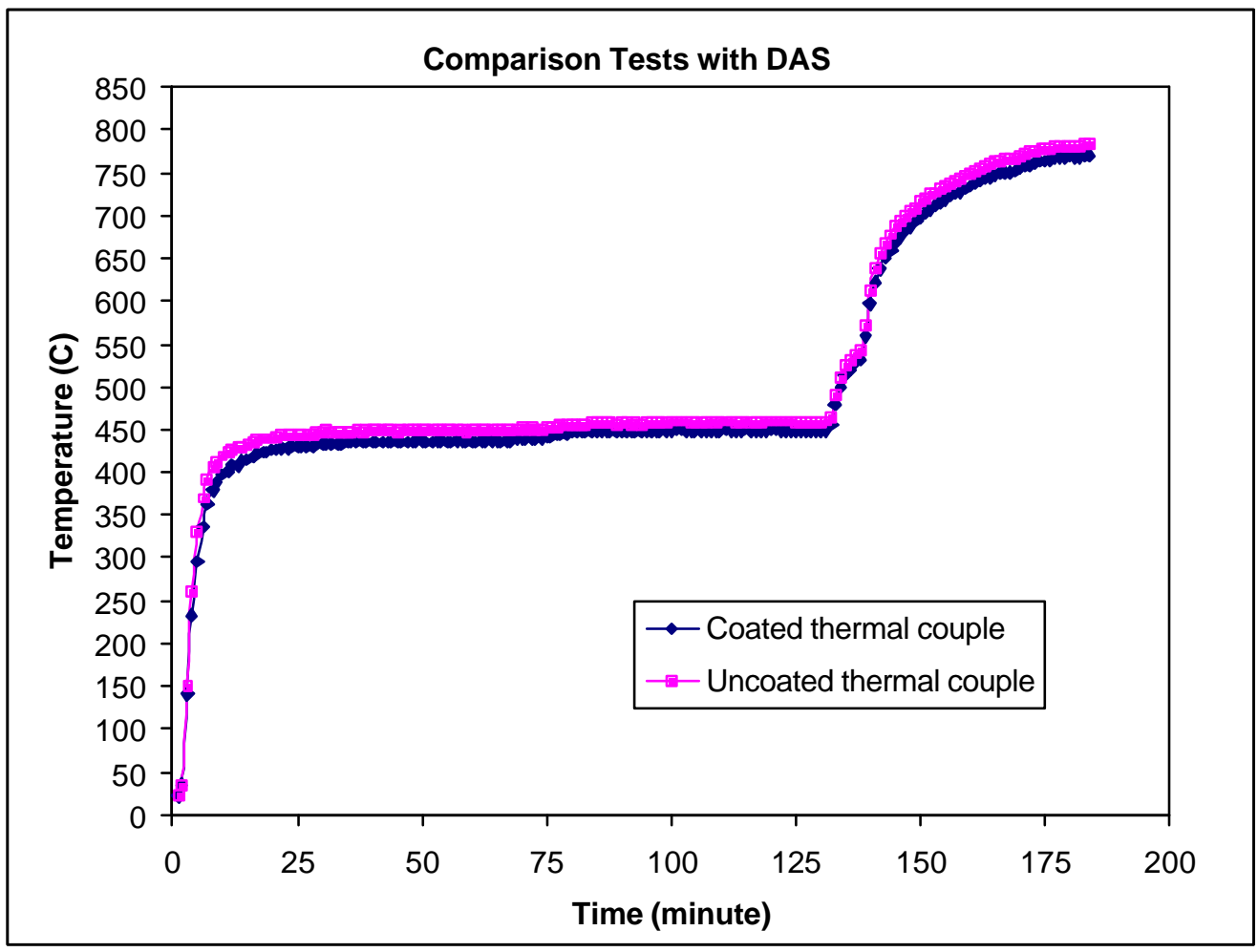

Figure 14 Comparison Tests of Coated/Uncoated Thermal Couple with DAS 


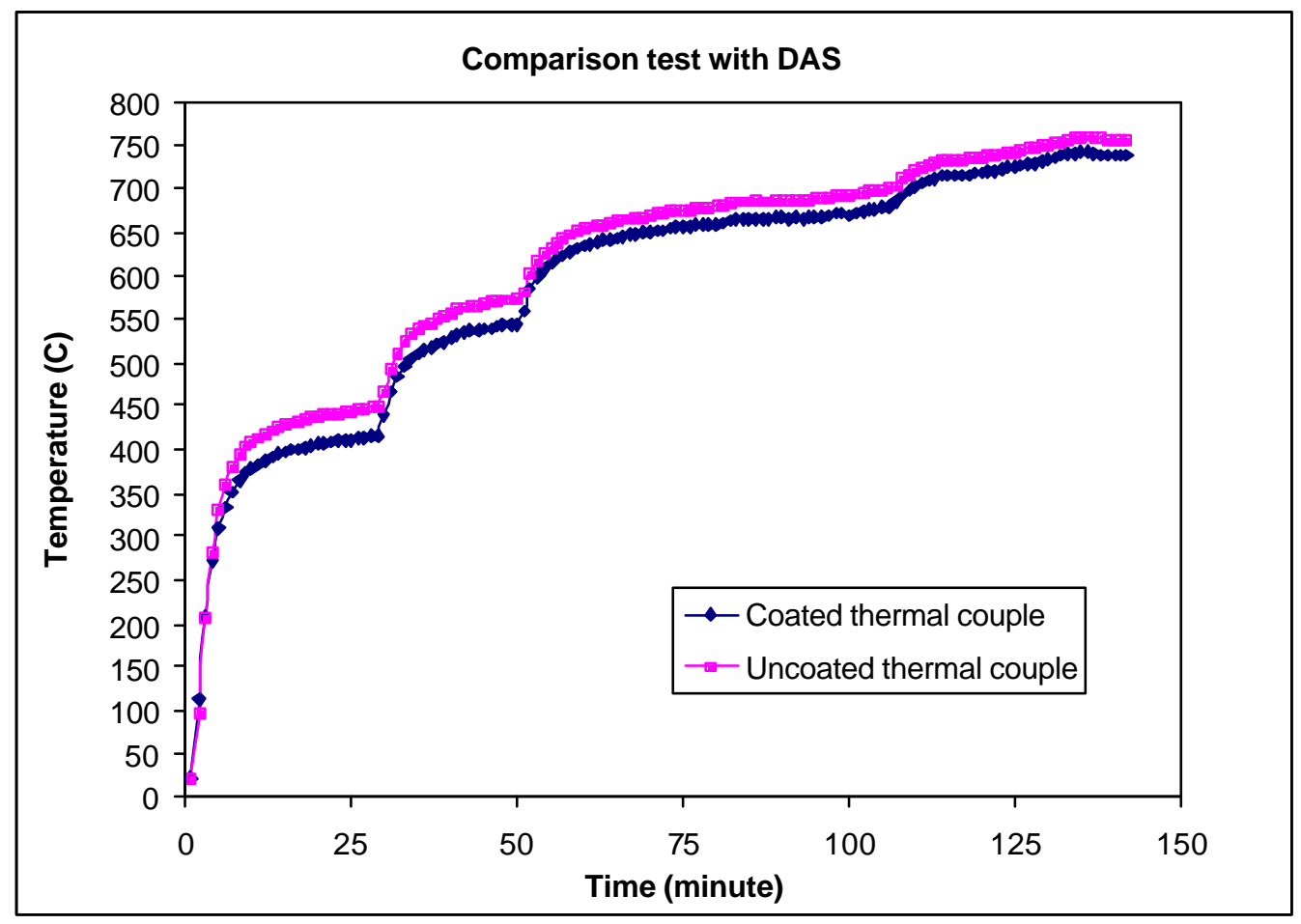

Figure 15 Comparison Tests of Coated/Uncoated Thermal Couple with DAS

\subsection{Analysis of Variance (ANOVA)}

ANOVA is used to uncover the main and interaction effects of the independent variables (called "factors") on an interval dependent variable (i.e. temperature difference)[12-13]. Table 2 shows the overall experiments results of the comparison of coated and uncoated thermal couples. Eight (8) experiments were conducted. The temperature difference between the coated and uncoated thermal couples is the real time average value of difference.

In order to test whether the inside environments or operation conditions will affect the temperature measurement of the coated thermal couple, the temperature difference of two thermal couples were calculated. Furthermore, the temperature difference was 
computed with regard to different operational parameters such as air flow rate, water/ammonia flow rate and fine dust particles addition. The statistical software SPSS was used to compute the ANOVA Table as shown in Table 3. Table 3 includes column of parameter, sum of squared errors, degree of freedom (df), mean squared errors, F-test and significant level.

From the ANOVA Table, the factors of air flow rate, water/ammonia and fine dust are considered as non-significant factors at the type I error of $\alpha=0.05$. This result indicates that the coated thermal couple does not affected by the operational parameters. Therefore, it is concluded that the coated thermal couple could be used to measure the temperate in the reducing and harsh environment.

Table 2 Average Temperature Difference of Coated and Uncoated Thermal Couple

\begin{tabular}{|c|c|c|c|c|}
\hline \multirow{2}{*}{$\begin{array}{c}\text { No. of } \\
\text { experiments }\end{array}$} & Air flow & $\begin{array}{c}\text { Ammonia/water } \\
\text { flow }\end{array}$ & $\begin{array}{c}\text { Fine dust particles } \\
\text { amount }\end{array}$ & $\begin{array}{c}\text { Averaged } \\
\text { temperature } \\
\text { difference }\end{array}$ \\
\cline { 2 - 5 } & Voltage & Ml/minute & gram & C \\
\hline 1 & 15 & 2 & 75 & 15.4 \\
\hline 2 & 10 & 2 & 75 & 9.4 \\
\hline 3 & 15 & 3 & 75 & 23.2 \\
\hline 4 & 10 & 3 & 75 & 10.4 \\
\hline 5 & 15 & 2 & 150 & 9.0 \\
\hline 6 & 10 & 2 & 150 & 12.9 \\
\hline 7 & 15 & 3 & 150 & 22.0 \\
\hline 8 & 10 & 3 & 150 & \\
\hline
\end{tabular}


Table 3 Analysis of Variance Table for the Comparison Tests

\begin{tabular}{|l|r|c|r|r|l|}
\hline Parameters & \multicolumn{1}{|c|}{$\begin{array}{c}\text { Sum of } \\
\text { Squares }\end{array}$} & Df & $\begin{array}{c}\text { Mean } \\
\text { Square }\end{array}$ & \multicolumn{1}{c|}{$\mathrm{F}$} & Sig. \\
\hline Corrected Model & $172.125(\mathrm{a})$ & 3 & 57.375 & 3.437 & .132 \\
Intercept & 1540.125 & 1 & 1540.125 & 92.264 & .001 \\
AirFlow & 99.405 & 1 & 99.405 & 5.955 & .071 \\
WaterAmmonia & 72.000 & 1 & 72.000 & 4.313 & .106 \\
FineDust & .720 & 1 & .720 & .043 & .846 \\
Error & 66.770 & 4 & 16.693 & & \\
Total & 1779.020 & 8 & & & \\
Corrected Total & 238.895 & 7 & & & \\
\hline
\end{tabular}

a R Squared $=.721$ (Adjusted R Squared $=.511$ ) 


\section{CONCLUSIONS:}

The major accomplishments in this semi-annual period are listed below:

1. The effects of the coated thermal couple of high velocity oxygen flow coating spray are being successively conducted during this semi-annual reporting period.

2. The temperature differences between the coated thermal couple and uncoated thermal couple are uniformly distributed throughout the whole testing process under various test conditions.

3. Analysis of variance (ANOVA) is an effective statistical tool to analyze the experimental data of dependent variable with regards to the independent variables (factors). The F-test is a powerful test to screen out the significant factors and/or significant interactions, which most affect the dependent variable.

4. The ANOVA results of temperature differences between the coated thermal couple and uncoated thermal couple are not statistically significant to the different combination of factors, which indicates that the coated thermal couple could be applied to the temperature measurement in gasifier. The real temperature from the coated thermal couple could be calibrated by a constant.

5. The computerized data acquisition system (DAS) is designed and applied to the comparison test of the coated and uncoated thermal couples. The DAS is very useful and accurate for data recording and analysis. 


\section{REFERENCES:}

1. Chrome Plating Alternative Thermal Spray:

http://www..faculty.rsu.edu/ clayton/kalivas/paper.htm

2. http://www.fe.doe.gov/coal_power/special_rpts/market_systems/market_sys.shtm

3. High Velocity Oxygen Fuel Thermal Spray Process: http://www.gordonengland..co.uk/hvof.htm

4. R. Ghafouri-Azar, J. Mostaghimi and S. Chandra, Modeling development of residual stresses in thermal spray coatings, Computational Materials Science, Volume 35, Issue 1, January 2006, Pages 13-26

5. J. Vicenzi, D.L. Villanova, M.D. Lima, A.S. Takimi, C.M. Marques and C.P. Bergmann, HVOF-coatings against high temperature erosion $\left(\sim 300{ }^{\circ} \mathrm{C}\right)$ by coal fly ash in thermoelectric power plant, Materials \& Design, Volume 27, Issue 3, 2006, Pages 236-242

6. Josep A. Picas, Antonio Forn, Ramiro Rilla and Enric Martín, HVOF thermal sprayed coatings on aluminium alloys and aluminium matrix composites Surface and Coatings Technology, Vol. 200, Issues 1-4, 1 October 2005, Pages 1178-1181

7. Lee, S.W., and B.Q. Wang, "Erosion of AISI 1018 Steel and Several Thermal Sprayed Coatings under Simulated In-Bed Tube Erosion Conditions of Fluidized Bed Combustors", presented at 13th Int'L Conference FBC. Kissimmee, FL, May 7-10, 1995, Book FBC-Vol. 2, pp. 1427-1432.

8. Lee, S.W., Semi-Annual Report: 'Innovative Instrumentation and Analysis of the Temperature Measurement for High Temperature Gasification", DOE report, April 04

9. Lee, S. W., "Innovative Instrumentation and Analysis of the Temperature Measurement for High Temperature Gasification” DOE Progress Report II, April 03.

10. Williams, A., M. Pourkashanian, N. Skorupska, Combustion and Gasification of Coal, Taylor \& Francis; ISBN: 1560325496, May 2000.

11. User's Guide, OMB-DAQ-54/55/56 quick start guide. Omega, 2005

12. Zhu, S., Y. Liu, J. Ngeru, and S.W. Lee, "Innovative High Temperature Measurement and Analysis in a Gasifier Simulator", presented and published in the Proceedings of $11^{\text {th }}$ Annual Undergraduate and Graduate Science Research Symposium, April 2004, Baltimore, MD.

13. D. C. Montgomery, Design and Analysis of Experiments, $6^{\text {th }}$ edition, John Willey and Sons, Inc., 2004 
Appendix 1: Experiment Results of Comparison Tests on Coated/Uncoated Thermal Couple

\begin{tabular}{|c|c|c|c|c|c|c|}
\hline \multirow{3}{*}{ Time } & \multicolumn{2}{|c|}{ Air flow: 15 voltage control } & \multicolumn{2}{|c|}{ Air flow: 10 voltage control } & \multicolumn{2}{c|}{ Air flow: 15 voltage control } \\
\cline { 2 - 7 } & ammonia/water: $2 \mathrm{ml} / \mathrm{min}$ & \multicolumn{2}{c|}{ ammonia/water: $2 \mathrm{ml} / \mathrm{min}$} & \multicolumn{2}{c|}{ ammonia/water: 3ml/min } \\
\cline { 2 - 7 } & Particles: 75 gram & \multicolumn{2}{|c|}{ Particles: 75 gram } & \multicolumn{2}{|c|}{ Particles: 75 gram } \\
\cline { 2 - 7 } & coated & original & coated & original & coated & original \\
\hline 0 & 26.2 & 20.0 & 201.1 & 312.8 & 118.3 & 54.6 \\
\hline 1 & 237.8 & 311.7 & 368.3 & 462.8 & 147.8 & 71.0 \\
\hline 2 & 384.6 & 380.0 & 455.8 & 520.0 & 171.7 & 84.3 \\
\hline 3 & 474.4 & 495.3 & 504.0 & 545.6 & 201.7 & 100.9 \\
\hline 4 & 538.9 & 533.1 & 537.8 & 573.9 & 225.6 & 114.2 \\
\hline 5 & 571.1 & 579.4 & 556.1 & 588.9 & 288.9 & 149.4 \\
\hline 10 & 650.6 & 654.4 & 627.8 & 651.1 & 332.6 & 358.5 \\
\hline 15 & 694.4 & 702.8 & 672.8 & 690.6 & 552.2 & 559.4 \\
\hline 20 & 728.3 & 734.4 & 707.2 & 720.0 & 630.0 & 640.0 \\
\hline 25 & 754.4 & 762.8 & 732.2 & 745.6 & 678.9 & 687.8 \\
\hline 30 & 776.1 & 782.8 & 761.1 & 766.7 & 710.6 & 720.6 \\
\hline 35 & 795.6 & 803.9 & 773.3 & 778.3 & 735.0 & 744.4 \\
\hline 40 & 813.3 & 821.7 & 793.9 & 797.2 & 767.8 & 777.8 \\
\hline 45 & 827.8 & 836.1 & 809.4 & 809.4 & 780.6 & 790.0 \\
\hline 50 & 842.8 & 850.6 & 825.0 & 818.3 & 790.6 & 800.6 \\
\hline 55 & 853.3 & 861.1 & 833.9 & 832.2 & 800.6 & 809.4 \\
\hline 60 & 863.3 & 871.1 & 840.6 & 843.3 & 808.9 & 819.4 \\
\hline 65 & 871.7 & 879.4 & 848.9 & 850.6 & 815.6 & 825.0 \\
\hline 70 & 876.7 & 884.4 & 856.1 & 857.2 & 821.1 & 830.0 \\
\hline 75 & 878.3 & 886.7 & 861.1 & 862.2 & 822.2 & 832.2 \\
\hline 80 & 881.1 & 890.0 & 866.7 & 870.6 & 827.2 & 835.6 \\
\hline 85 & 868.3 & 878.9 & 875.6 & 876.7 & & \\
\hline 90 & 863.9 & 875.0 & 882.2 & 883.3 & & \\
\hline 95 & 868.9 & 878.9 & 886.7 & 887.8 & & \\
\hline 100 & 866.7 & 879.4 & 890.0 & 890.6 & & \\
\hline 105 & 869.4 & 877.8 & 894.4 & 895.0 & & \\
\hline 110 & & & 898.9 & 898.3 & & \\
\hline 115 & & & 902.2 & 901.7 & & \\
\hline 120 & & & 906.1 & 903.9 & & \\
\hline 125 & & & 908.3 & 906.7 & & \\
\hline & & & & & & \\
\hline
\end{tabular}


Appendix 2: Experiment Results of Comparison Tests on Coated/Uncoated Thermal Couple with DAS

\begin{tabular}{|c|c|c|c|c|c|c|c|c|c|c|}
\hline \multirow{2}{*}{ Time } & \multicolumn{2}{|c|}{ Test \# 4} & \multicolumn{2}{|c|}{ Test \# 5} & \multicolumn{2}{|c|}{ Test \# 6} & \multicolumn{2}{|c|}{ Test \# 7} & \multicolumn{2}{|c|}{ Test \# 8} \\
\hline & A02 & A04 & $\mathrm{A} 02$ & A04 & A02 & A04 & A02 & A04 & A02 & A04 \\
\hline minute & ${ }^{\circ} \mathrm{C}$ & ${ }^{\circ} \mathrm{C}$ & ${ }^{\circ} \mathrm{C}$ & ${ }^{\circ} \mathrm{C}$ & ${ }^{\circ} \mathrm{C}$ & ${ }^{\circ} \mathrm{C}$ & ${ }^{\circ} \mathrm{C}$ & ${ }^{\circ} \mathrm{C}$ & ${ }^{\circ} \mathrm{C}$ & ${ }^{\circ} \mathrm{C}$ \\
\hline 1 & 232.0 & 202.7 & 22.9 & 23.0 & 22.8 & 22.8 & 22.3 & 22.3 & 22.1 & 21.9 \\
\hline 2 & 297.8 & 293.5 & 23.0 & 23.0 & 22.9 & 22.9 & 35.4 & 35.2 & 112.4 & 98.1 \\
\hline 3 & 459.3 & 486.0 & 22.9 & 23.0 & 22.8 & 22.7 & 141.9 & 149.9 & 207.8 & 205.8 \\
\hline 4 & 555.9 & 592.9 & 22.9 & 22.9 & 22.8 & 22.8 & 233.6 & 259.1 & 270.8 & 283.0 \\
\hline 5 & 610.1 & 647.9 & 22.9 & 22.9 & 22.8 & 22.8 & 296.3 & 329.2 & 310.3 & 331.7 \\
\hline 6 & 643.2 & 680.1 & 46.2 & 51.3 & 22.8 & 22.8 & 337.4 & 369.7 & 333.5 & 360.0 \\
\hline 7 & 665.8 & 701.8 & 189.7 & 201.1 & 22.8 & 22.8 & 363.0 & 392.2 & 351.8 & 379.8 \\
\hline 8 & 683.5 & 716.5 & 306.9 & 309.2 & 22.8 & 22.9 & 378.9 & 405.3 & 365.1 & 393.8 \\
\hline 9 & 698.0 & 730.1 & 383.7 & 374.1 & 22.8 & 22.9 & 389.0 & 412.6 & 374.4 & 403.3 \\
\hline 10 & 711.1 & 741.9 & 427.6 & 413.9 & 22.8 & 22.8 & 397.2 & 418.9 & 378.7 & 409.2 \\
\hline 11 & 722.1 & 751.8 & 453.7 & 454.0 & 22.8 & 22.8 & 402.3 & 423.0 & 382.6 & 412.9 \\
\hline 12 & 732.3 & 760.9 & 471.2 & 476.0 & 72.6 & 72.4 & 407.3 & 426.4 & 387.7 & 418.3 \\
\hline 13 & 741.3 & 769.3 & 483.2 & 483.0 & 193.8 & 213.8 & 409.2 & 428.4 & 391.7 & 422.4 \\
\hline 14 & 749.3 & 776.6 & 493.7 & 494.0 & 287.9 & 326.7 & 412.9 & 430.3 & 395.3 & 426.2 \\
\hline 15 & 756.5 & 783.1 & 501.2 & 509.0 & 352.3 & 395.3 & 415.6 & 432.4 & 397.8 & 429.1 \\
\hline 16 & 763.1 & 789.1 & 506.1 & 509.0 & 389.0 & 425.1 & 417.9 & 434.4 & 399.2 & 431.2 \\
\hline 17 & 768.8 & 794.3 & 512.4 & 511.0 & 411.2 & 436.5 & 420.6 & 436.4 & 401.0 & 432.9 \\
\hline 18 & 774.2 & 799.4 & 516.4 & 527.0 & 426.1 & 446.9 & 422.8 & 438.6 & 402.2 & 434.5 \\
\hline 19 & 779.1 & 804.0 & 521.8 & 536.0 & 438.6 & 456.4 & 424.2 & 439.7 & 404.8 & 436.8 \\
\hline 20 & 784.0 & 808.5 & 526.6 & 542.0 & 444.7 & 460.7 & 425.7 & 440.4 & 405.9 & 438.3 \\
\hline 21 & 788.5 & 812.6 & 532.3 & 551.0 & 448.4 & 464.0 & 426.8 & 440.8 & 407.5 & 439.9 \\
\hline 22 & 792.9 & 816.7 & 536.4 & 558.5 & 451.7 & 466.5 & 427.8 & 443.0 & 409.2 & 441.0 \\
\hline 23 & 797.0 & 820.4 & 543.8 & 566.7 & 454.6 & 469.4 & 428.8 & 443.4 & 411.4 & 443.0 \\
\hline 24 & 801.0 & 824.0 & 546.9 & 569.5 & 458.2 & 472.5 & 430.1 & 443.5 & 410.0 & 443.2 \\
\hline 25 & 802.9 & 826.3 & 550.5 & 572.4 & 461.2 & 476.1 & 430.2 & 444.0 & 412.1 & 444.5 \\
\hline 26 & 806.0 & 829.1 & 554.3 & 575.3 & 470.2 & 481.8 & 429.7 & 443.5 & 414.0 & 446.1 \\
\hline 27 & 809.4 & 832.3 & 557.6 & $\begin{array}{l}577.8 \\
\end{array}$ & 477.1 & 488.7 & 430.9 & 444.4 & 413.3 & 446.3 \\
\hline 28 & 812.3 & 834.9 & 559.8 & 578.9 & 482.7 & 493.5 & 430.6 & 443.9 & 415.0 & 448.0 \\
\hline 29 & 815.3 & 837.7 & $\begin{array}{l}563.6 \\
\end{array}$ & 581.1 & 486.1 & 496.5 & 432.3 & 445.8 & 416.1 & 448.3 \\
\hline 30 & 818.0 & 840.3 & 568.5 & 582.6 & 488.5 & 499.1 & 432.3 & 445.6 & 438.7 & 465.9 \\
\hline 31 & 820.7 & 842.7 & 570.8 & 584.7 & 488.6 & 501.6 & 433.4 & 447.6 & 466.2 & 492.9 \\
\hline 32 & 823.4 & 845.3 & 573.0 & 586.5 & 490.2 & 503.6 & 433.5 & 446.4 & 485.0 & 511.2 \\
\hline 33 & 826.0 & 847.7 & 575.4 & 589.2 & 492.7 & 505.6 & 433.5 & 446.0 & 496.1 & 523.2 \\
\hline 34 & 828.1 & 849.6 & 577.6 & 591.2 & 494.1 & 506.6 & 433.4 & 447.0 & 504.4 & 532.4 \\
\hline 35 & 829.7 & 851.2 & 579.2 & 593.5 & 495.7 & 508.1 & 434.1 & 447.0 & 511.0 & 538.8 \\
\hline 36 & 831.7 & 853.2 & 582.2 & 596.4 & 497.2 & 509.2 & 435.0 & 447.1 & 514.6 & 543.2 \\
\hline 37 & 833.4 & 854.7 & 584.3 & 598.3 & 498.4 & 510.2 & 434.8 & 447.6 & 516.5 & 546.1 \\
\hline 38 & 835.3 & 856.5 & 586.4 & 599.3 & 499.4 & 511.6 & 435.3 & 447.4 & 521.9 & 550.0 \\
\hline 39 & 837.4 & 858.4 & 587.3 & 600.0 & 500.7 & 511.9 & 435.2 & 447.8 & 524.8 & 553.4 \\
\hline 40 & 839.0 & 859.9 & 588.3 & 601.7 & 502.0 & 513.6 & 435.2 & 448.0 & 528.6 & 557.0 \\
\hline 41 & 841.1 & 861.7 & 590.2 & 603.3 & 503.3 & 514.6 & 435.7 & 448.2 & 532.3 & 560.7 \\
\hline
\end{tabular}




\begin{tabular}{|c|c|c|c|c|c|c|c|c|c|c|}
\hline 42 & 842.5 & 863.1 & 591.7 & 604.7 & 504.5 & 515.7 & 435.9 & 448.4 & 534.8 & 563.0 \\
\hline 43 & 844.6 & 865.0 & 593.0 & 605.3 & 506.9 & 517.2 & 436.2 & 448.9 & 536.6 & 565.1 \\
\hline 44 & 845.9 & 866.3 & 594.7 & 607.2 & 507.7 & 517.7 & 435.9 & 448.1 & 537.6 & 566.5 \\
\hline 45 & 847.3 & 867.6 & 595.4 & 607.9 & 508.4 & 518.3 & 435.3 & 447.1 & 539.1 & 568.1 \\
\hline 46 & 850.3 & 870.1 & 596.7 & 609.0 & 509.4 & 518.5 & 436.0 & 447.8 & 539.9 & 569.7 \\
\hline 47 & 859.8 & 877.5 & 598.3 & 609.9 & 510.0 & 519.2 & 436.0 & 448.2 & 542.2 & 571.1 \\
\hline 48 & 863.3 & 881.1 & 598.0 & 609.9 & 511.7 & 521.1 & 436.0 & 448.1 & 542.8 & 572.1 \\
\hline 49 & 858.1 & 877.5 & 598.4 & 610.3 & 513.4 & 523.0 & 436.6 & 448.5 & 544.0 & 573.4 \\
\hline 50 & 853.3 & 873.4 & 600.3 & 611.5 & 530.7 & 541.9 & 436.2 & 447.7 & 544.1 & 574.4 \\
\hline 51 & 849.9 & 890.2 & 600.3 & 611.9 & 544.7 & 556.6 & 435.9 & 448.2 & 559.4 & 581.3 \\
\hline 52 & & & 601.3 & 613.1 & 553.5 & 565.3 & 436.0 & 448.5 & 585.4 & 602.7 \\
\hline 53 & & & 602.3 & 613.5 & 560.2 & 572.1 & 436.2 & 448.5 & 599.6 & 616.8 \\
\hline 54 & & & 604.5 & 615.4 & 566.0 & 577.6 & 436.6 & 448.5 & 608.1 & 625.6 \\
\hline 55 & & & 606.0 & 617.0 & 569.9 & 582.0 & 435.7 & 448.2 & 614.8 & 632.5 \\
\hline 56 & & & 607.8 & 618.5 & 573.4 & 584.8 & 435.8 & 448.4 & 621.1 & 638.4 \\
\hline 57 & & & 608.6 & 619.4 & 576.4 & 587.2 & 436.9 & 448.0 & 623.4 & 642.6 \\
\hline 58 & & & 609.5 & 620.5 & 578.5 & 589.3 & 436.7 & 448.0 & 628.5 & 647.1 \\
\hline 59 & & & 610.7 & 621.5 & 581.3 & 592.5 & 435.6 & 447.2 & 631.5 & 650.8 \\
\hline 60 & & & 610.9 & 621.3 & 583.8 & 594.6 & 435.0 & 447.9 & 635.1 & 654.2 \\
\hline 61 & & & 611.7 & 622.1 & 586.5 & 596.6 & 435.3 & 448.0 & 636.2 & 656.3 \\
\hline 62 & & & 611.7 & 622.2 & 589.0 & 600.2 & 436.4 & 449.0 & 638.5 & 658.3 \\
\hline 63 & & & 612.5 & 622.5 & 591.7 & 602.3 & 437.3 & 449.2 & 640.5 & 659.1 \\
\hline 64 & & & 612.3 & 622.1 & 594.3 & 605.5 & 437.2 & 449.2 & 640.7 & 660.1 \\
\hline 65 & & & 613.1 & 622.8 & 596.8 & 607.5 & 436.3 & 448.1 & 643.0 & 662.4 \\
\hline 66 & & & 613.5 & 623.4 & 599.7 & 610.6 & 436.0 & 448.9 & 644.9 & 664.1 \\
\hline 67 & & & 614.1 & 624.1 & 602.6 & 613.3 & 437.2 & 449.6 & 646.6 & 665.6 \\
\hline 68 & & & 618.1 & 631.7 & 604.4 & 615.3 & 438.4 & 450.7 & 647.5 & 666.6 \\
\hline 69 & & & 623.5 & 636.5 & 605.8 & 616.9 & 439.0 & 451.0 & 649.5 & 668.3 \\
\hline 70 & & & 627.0 & 639.7 & 607.6 & 618.1 & 439.5 & 452.0 & 650.4 & 669.7 \\
\hline 71 & & & 629.6 & 642.4 & 609.0 & 619.6 & 439.3 & 451.5 & 651.7 & 671.2 \\
\hline 72 & & & 631.1 & 643.3 & 610.5 & 620.3 & 439.8 & 452.0 & 652.9 & 672.1 \\
\hline 73 & & & 633.2 & 645.7 & 610.8 & 620.8 & 439.4 & 451.0 & 655.1 & 673.9 \\
\hline 74 & & & 635.1 & 647.3 & 611.9 & 622.0 & 440.0 & 451.4 & 656.8 & 675.8 \\
\hline 75 & & & 637.1 & 648.8 & 612.6 & 622.1 & 441.4 & 452.6 & 656.5 & 676.3 \\
\hline 76 & & & 637.9 & 649.6 & 613.2 & 622.1 & 442.0 & 452.9 & 657.0 & 677.1 \\
\hline 77 & & & 639.6 & 651.0 & 614.1 & 623.1 & 443.4 & 454.0 & 657.5 & 677.5 \\
\hline 78 & & & 640.1 & 651.4 & 614.9 & 623.6 & 444.2 & 454.2 & 657.9 & 678.1 \\
\hline 79 & & & 640.2 & 651.2 & 614.7 & 623.6 & 445.1 & 454.8 & 658.9 & 678.9 \\
\hline 80 & & & 640.5 & 651.4 & 615.0 & 623.7 & 445.8 & 455.8 & 659.5 & 679.7 \\
\hline 81 & & & 641.1 & 652.0 & 615.7 & 624.4 & 445.2 & 455.6 & 661.1 & 680.9 \\
\hline 82 & & & 640.8 & 651.6 & 617.0 & 626.1 & 445.2 & 455.6 & 663.7 & 683.0 \\
\hline 83 & & & 641.6 & 652.2 & 618.4 & 627.6 & 446.1 & 456.1 & 664.8 & 684.3 \\
\hline 84 & & & 641.4 & 652.5 & 619.9 & 628.7 & 447.0 & 456.5 & 665.4 & 685.0 \\
\hline 85 & & & 642.6 & 653.1 & 620.4 & 629.3 & 447.3 & 457.4 & 665.0 & 685.5 \\
\hline 86 & & & 643.0 & 653.8 & 621.8 & 631.1 & 447.8 & 458.1 & 665.8 & 686.4 \\
\hline 87 & & & 643.4 & 654.4 & 623.6 & 632.5 & 448.0 & 457.9 & 665.4 & 685.8 \\
\hline 88 & & & 645.2 & 655.8 & 624.6 & 633.2 & 447.6 & 456.8 & 665.6 & 686.1 \\
\hline 89 & & & 645.9 & 657.2 & 625.2 & 633.9 & 447.1 & 456.2 & 666.9 & 686.8 \\
\hline
\end{tabular}




\begin{tabular}{|c|c|c|c|c|c|c|c|c|}
\hline 90 & 646.7 & 658.3 & 626.5 & 635.0 & 446.9 & 457.2 & 666.7 & 687.1 \\
\hline 91 & 648.4 & 659.7 & 627.1 & 635.8 & 447.0 & 456.6 & 665.7 & 686.9 \\
\hline 92 & 649.6 & 660.1 & 627.3 & 636.1 & 446.0 & 455.8 & 667.3 & 687.7 \\
\hline 93 & 649.7 & 660.5 & 627.9 & 636.4 & 446.8 & 456.6 & 666.1 & 687.6 \\
\hline 94 & 650.9 & 661.8 & 628.5 & 636.7 & 446.3 & 456.1 & 666.5 & 688.1 \\
\hline 95 & 651.8 & 662.2 & 628.6 & 636.7 & 447.7 & 457.8 & 667.6 & 688.6 \\
\hline 96 & 652.1 & 662.7 & 628.4 & 636.8 & 447.3 & 457.1 & 667.4 & 688.8 \\
\hline 97 & 652.5 & 663.5 & 628.3 & 635.9 & 448.4 & 458.3 & 669.8 & 690.5 \\
\hline 98 & 653.6 & 664.2 & 628.5 & 636.3 & 448.2 & 457.8 & 672.4 & 692.6 \\
\hline 99 & 654.2 & 665.2 & 628.9 & 636.2 & 449.1 & 458.5 & 671.5 & 692.8 \\
\hline 100 & 655.2 & 665.8 & 629.0 & 635.8 & 448.9 & 458.9 & 670.4 & 691.9 \\
\hline 101 & 655.2 & 665.6 & 628.6 & 635.8 & 450.5 & 459.9 & 672.9 & 693.5 \\
\hline 102 & 655.7 & 666.3 & 628.9 & 636.2 & 449.8 & 459.3 & 674.2 & 695.1 \\
\hline 103 & 655.5 & 665.8 & 628.9 & 635.9 & 449.3 & 459.5 & 675.3 & 697.3 \\
\hline 104 & 656.4 & 666.7 & 628.6 & 635.2 & 449.3 & 458.4 & 676.1 & 698.3 \\
\hline 105 & 657.4 & 667.4 & 628.3 & 634.6 & 448.4 & 457.8 & 677.4 & 699.4 \\
\hline 106 & 657.5 & 667.9 & 629.0 & 635.4 & 448.9 & 458.5 & 678.2 & 699.8 \\
\hline 107 & 657.2 & 667.4 & 628.7 & 635.3 & 448.6 & 458.3 & 684.0 & 703.6 \\
\hline 108 & 657.0 & 667.5 & 629.2 & 635.2 & 449.4 & 458.8 & 692.1 & 710.7 \\
\hline 109 & 657.3 & 667.2 & 629.2 & 636.0 & 449.5 & 458.3 & 697.5 & 716.1 \\
\hline 110 & 656.8 & 666.9 & 629.9 & 636.4 & 449.6 & 459.2 & 702.1 & 721.0 \\
\hline 111 & 657.0 & 666.6 & 629.8 & 636.2 & 449.7 & 459.7 & 706.8 & 724.8 \\
\hline 112 & 656.7 & 666.8 & 630.3 & 636.3 & 449.6 & 459.2 & 708.7 & 726.8 \\
\hline 113 & 656.2 & 666.3 & 630.3 & 636.8 & 449.0 & 458.1 & 711.7 & 729.5 \\
\hline 114 & 656.9 & 667.2 & 631.4 & 637.6 & 449.2 & 458.3 & 715.4 & 732.8 \\
\hline 115 & 657.6 & 668.0 & 631.3 & 637.4 & 449.7 & 459.1 & 715.6 & 734.3 \\
\hline 116 & 658.1 & 668.5 & 632.1 & 638.1 & 449.1 & 458.4 & 716.1 & 734.5 \\
\hline 117 & 658.9 & 668.9 & 631.7 & 637.7 & 448.2 & 457.7 & 715.8 & 734.8 \\
\hline 118 & 658.7 & 668.4 & 632.2 & 638.0 & 448.1 & 457.5 & 716.1 & 734.9 \\
\hline 119 & 658.0 & 668.0 & 632.7 & 638.1 & 449.6 & 459.3 & 717.2 & 735.7 \\
\hline 120 & 657.7 & 667.5 & 632.6 & 638.2 & 449.8 & 458.8 & 718.1 & 736.6 \\
\hline 121 & 657.6 & 667.8 & 632.9 & 638.5 & 450.8 & 459.8 & 719.5 & 737.8 \\
\hline 122 & 658.4 & 668.1 & 633.0 & 638.8 & 449.4 & 458.8 & 720.5 & 738.8 \\
\hline 123 & 659.2 & 668.6 & 633.2 & 638.7 & 449.0 & 458.8 & 721.9 & 740.2 \\
\hline 124 & 659.1 & 669.1 & 632.9 & 639.1 & 449.6 & 459.2 & 724.1 & 742.0 \\
\hline 125 & 659.4 & 669.1 & 633.7 & 639.1 & 449.1 & 457.9 & 724.9 & 743.2 \\
\hline 126 & 660.0 & 670.2 & 634.0 & 639.7 & 448.1 & 457.7 & 726.3 & 744.6 \\
\hline 127 & 661.0 & 670.8 & 634.5 & 639.3 & 448.2 & 458.1 & 728.4 & 746.1 \\
\hline 128 & 662.3 & 672.6 & 634.1 & 639.9 & 448.2 & 457.6 & 730.2 & 747.6 \\
\hline 129 & 663.4 & 673.2 & 634.6 & 640.1 & 448.5 & 458.1 & 731.2 & 748.7 \\
\hline 130 & 663.2 & 672.9 & 634.8 & 640.7 & 448.5 & 458.2 & 732.8 & 750.4 \\
\hline 131 & 662.6 & 672.3 & 635.6 & 641.4 & 449.5 & 459.0 & 735.6 & 752.6 \\
\hline 132 & 661.8 & 671.1 & 636.2 & 642.5 & 454.5 & 463.7 & 737.4 & 754.6 \\
\hline 133 & 660.9 & 670.4 & 637.7 & 644.5 & 480.7 & 491.9 & 739.7 & 756.2 \\
\hline 134 & 661.3 & 671.0 & 639.5 & 646.2 & 500.7 & 511.6 & 741.1 & 757.5 \\
\hline 135 & 662.0 & 671.6 & 640.9 & 647.6 & 513.0 & 523.9 & 741.8 & 758.4 \\
\hline 136 & 662.3 & 672.0 & 641.2 & 647.5 & 521.4 & 532.0 & 742.6 & 759.3 \\
\hline 137 & 662.8 & 672.7 & 640.9 & 647.1 & 528.7 & 539.2 & 740.8 & 758.2 \\
\hline
\end{tabular}




\begin{tabular}{|c|c|c|c|c|c|c|c|c|}
\hline 138 & 663.8 & 673.6 & 640.5 & 646.7 & 532.6 & 543.0 & 738.9 & 756.9 \\
\hline 139 & 663.9 & 673.7 & 639.4 & 644.5 & 557.8 & 571.1 & 737.8 & 756.2 \\
\hline 140 & 662.0 & 672.1 & 638.9 & 643.7 & 596.9 & 612.0 & 738.2 & 756.2 \\
\hline 141 & 661.1 & 670.9 & 638.3 & 643.1 & 620.6 & 637.3 & 738.8 & 756.4 \\
\hline 142 & 661.1 & 671.0 & 638.4 & 643.4 & 637.6 & 654.6 & 738.4 & 756.3 \\
\hline 143 & 660.0 & 669.8 & 638.8 & 644.2 & 649.8 & 667.4 & & \\
\hline 144 & 660.1 & 669.5 & 639.0 & 644.3 & 659.9 & 677.6 & & \\
\hline 145 & 660.0 & 670.5 & 638.7 & 644.5 & 668.1 & 686.0 & & \\
\hline 146 & 661.2 & 670.8 & 639.0 & 644.5 & 675.7 & 693.0 & & \\
\hline 147 & 661.2 & 671.0 & 639.5 & 644.8 & 681.7 & 699.0 & & \\
\hline 148 & 661.5 & 671.6 & 639.8 & 645.1 & 687.1 & 704.3 & & \\
\hline 149 & 661.9 & 671.7 & 640.4 & 645.4 & 692.7 & 709.6 & & \\
\hline 150 & 661.7 & 671.2 & 640.3 & 645.7 & 697.8 & 714.7 & & \\
\hline 151 & 661.7 & 671.4 & 639.9 & 645.6 & 702.7 & 719.2 & & \\
\hline 152 & 661.6 & 671.0 & 640.3 & 645.7 & 707.1 & 723.6 & & \\
\hline 153 & 660.1 & 670.0 & 640.4 & 645.8 & 710.6 & 727.1 & & \\
\hline 154 & 659.8 & 669.7 & & & 714.5 & 730.6 & & \\
\hline 155 & 660.2 & 669.8 & & & 718.1 & 734.2 & & \\
\hline 156 & 659.6 & 669.5 & & & 721.7 & 737.6 & & \\
\hline 157 & 660.9 & 671.1 & & & 725.4 & 741.1 & & \\
\hline 158 & 660.8 & 670.2 & & & 727.7 & 743.4 & & \\
\hline 159 & 660.8 & 671.0 & & & 730.4 & 746.2 & & \\
\hline 160 & 661.7 & 671.4 & & & 733.7 & 749.0 & & \\
\hline 161 & 662.0 & 671.8 & & & 736.9 & 752.1 & & \\
\hline 162 & 661.0 & 670.6 & & & 739.5 & 754.4 & & \\
\hline 163 & 660.9 & 670.0 & & & 742.1 & 756.9 & & \\
\hline 164 & 660.2 & 669.5 & & & 745.0 & 759.8 & & \\
\hline 165 & 659.9 & 669.4 & & & 747.3 & 762.1 & & \\
\hline 166 & 660.0 & 669.5 & & & 748.7 & 763.5 & & \\
\hline 167 & 660.1 & 669.5 & & & 749.9 & 764.3 & & \\
\hline 168 & 660.1 & 670.0 & & & 749.9 & 764.2 & & \\
\hline 169 & 660.8 & 670.5 & & & 751.7 & 765.9 & & \\
\hline 170 & 661.1 & 670.8 & & & 754.9 & 768.9 & & \\
\hline 171 & 661.5 & 670.9 & & & 757.1 & 771.0 & & \\
\hline 172 & 660.3 & 669.9 & & & 758.8 & 772.6 & & \\
\hline 173 & 659.8 & 669.2 & & & 760.7 & 774.4 & & \\
\hline 174 & 659.8 & 669.3 & & & 761.5 & 775.6 & & \\
\hline 175 & 659.6 & 669.1 & & & 763.3 & 777.1 & & \\
\hline 176 & 662.8 & 673.3 & & & 764.8 & 778.3 & & \\
\hline 177 & 663.7 & 675.4 & & & 766.1 & 779.6 & & \\
\hline 178 & 665.5 & 677.2 & & & 767.3 & 780.8 & & \\
\hline 179 & 667.0 & 678.6 & & & 767.7 & 781.0 & & \\
\hline 180 & 665.0 & 682.0 & & & 768.2 & 781.3 & & \\
\hline 181 & 667.3 & 685.4 & & & 767.7 & 781.2 & & \\
\hline 182 & 669.6 & 686.9 & & & 768.0 & 781.4 & & \\
\hline 183 & & & & & 768.8 & 782.0 & & \\
\hline 184 & & & & & 768.7 & 781.9 & & \\
\hline
\end{tabular}

